\title{
Survival after liver resection in metastatic colorectal cancer: review and meta-analysis of prognostic factors
}

This article was published in the following Dove Press journal:

Clinical Epidemiology

6 November 2012

Number of times this article has been viewed

\author{
Gena P Kanas' \\ Aliki Taylor ${ }^{2}$ \\ John N Primrose ${ }^{3}$ \\ Wendy J Langeberg ${ }^{4}$ \\ Michael A Kelsh ${ }^{4}$ \\ Fionna S Mowat' \\ Dominik D Alexander ${ }^{5}$ \\ Michael A Choti ${ }^{6}$ \\ Graeme Poston ${ }^{7}$ \\ 'Health Sciences, Exponent, \\ Menlo Park, CA, USA; ${ }^{2}$ Centre for \\ Observational Research, Amgen, \\ Uxbridge, UK; ${ }^{3}$ Department of \\ Surgery, Southampton General \\ Hospital, Southampton, UK; ${ }^{4}$ Center \\ for Observational Research, Amgen, \\ Thousand Oaks, CA, USA; ${ }^{5} \mathrm{Health}$ \\ Sciences, Exponent, Chicago, IL, USA \\ ${ }^{6} J o h n s$ Hopkins Hospital, Baltimore, \\ MD, USA; ' Department of Surgery, \\ Aintree University Hospitals NHS, \\ Liverpool, UK
}

Correspondence: Aliki Taylor

Centre for Observational Research, Amgen, I Uxbridge Business Park, Sanderson Road, Uxbridge UB8 IDH, UK

Tel +44 I895 525482

Fax +44 I895 525 I04

Email alikit@amgen.com
Background: Hepatic metastases develop in approximately $50 \%$ of colorectal cancer (CRC) cases. We performed a review and meta-analysis to evaluate survival after resection of CRC liver metastases (CLMs) and estimated the summary effect for seven prognostic factors.

Methods: Studies published between 1999 and 2010, indexed on Medline, that reported survival after resection of CLMs, were reviewed. Meta-relative risks for survival by prognostic factor were calculated, stratified by study size and annual clinic volume. Cumulative meta-analysis results by annual clinic volume were plotted.

Results: Five- and 10-year survival ranged from 16\% to $74 \%$ (median 38\%) and $9 \%$ to $69 \%$ (median 26\%), respectively, based on 60 studies. The overall summary median survival time was 3.6 (range: 1.7-7.3) years. Meta-relative risks (95\% confidence intervals) by prognostic factor were: node positive primary, 1.6 (1.5-1.7); carcinoembryonic antigen level, 1.9 (1.1-3.2); extrahepatic disease, 1.9 (1.5-2.4); poor tumor grade, 1.9 (1.3-2.7); positive margin, 2.0 (1.7-2.5); >1 liver metastases, 1.6 (1.4-1.8); and $>3 \mathrm{~cm}$ tumor diameter, 1.5 (1.3-1.8). Cumulative meta-analyses by annual clinic volume suggested improved survival with increasing volume.

Conclusion: The overall median survival following CLM liver resection was 3.6 years. All seven investigated prognostic factors showed a modest but significant predictive relationship with survival, and certain prognostic factors may prove useful in determining optimal therapeutic options. Due to the increasing complexity of surgical interventions for CLM and the inclusion of patients with higher disease burdens, future studies should consider the potential for selection and referral bias on survival.

Keywords: metastatic colorectal cancer, liver resection, survival, meta-analysis

\section{Introduction}

Hepatic metastases develop in approximately $50 \%$ of colorectal cancer cases, ${ }^{1,2}$ with $20 \%-25 \%$ of newly diagnosed metastatic colorectal cancer (mCRC) patients presenting with liver metastases at the time of primary diagnosis, and up to $50 \%$ of all CRC patients developing metastatic liver disease after resection of primary CRC. ${ }^{2-4}$ Among those with liver-limited colorectal metastases, it has been reported that $10 \%-30 \%$ of patients have potentially resectable disease that can be treated with curative intent at the time of detection. ${ }^{5-9}$ Among those patients with successful resection of all evident metastatic disease, long-term survival appears to be improving, with 5-year survival reported to be over $50 \%$ in recent studies. . $^{2,3,10-14}$

The purpose of this review was to evaluate studies published in the past decade (1999-2010) that report survival of patients with liver resections for colorectal liver 
metastases (CLMs). The current analysis updates information on survival from a published review of these data in $2006 .^{15}$ We estimated the association between seven prognostic factors reported to be predictors of survival ${ }^{2,4,16,17}$ in this patient population, using meta-analysis techniques. Our analysis also sought to evaluate the impact of annual clinic volume on the association between prognostic factors and survival.

\section{Materials and methods}

\section{Literature search strategy}

Peer-reviewed English-language papers published between January 1, 1999 and May 31, 2010 that reported survival after surgical resection of CLM were identified using Medline, accessed through PubMed. No review protocol is available. All overlapping studies reported in the Simmonds et $\mathrm{al}^{15}$ review that met the basic inclusion criteria of the current analysis were also included. The main search strategy used the following keywords: surgery, resection, hepatectomy, colon cancer, colorectal cancer, rectal cancer, metastatic, mestastases, mortality, and survival. The full search strategy is included in the Supplementary material. The bibliographies of identified articles were examined to identify additional literature. Reviews, meta-analyses, and case reports were excluded, although their reference lists were reviewed for additional studies. Case series were included, but were required to report on at least ten patients.

\section{Inclusion criteria}

Our inclusion criteria were:

1. original publication (no reviews or commentaries);

2. clinical trials, case-control or cohort observational studies;

3. case series of at least ten patients;

4. study populations aged at least 18 years;

5. patients with CLM;

6. patients with surgical liver resection;

7. median or mean follow-up time of at least 24 months; and

8. reported outcome measures of overall and disease-free survival.

If multiple publications reported results for survival after liver resection in the same population, the most recent report or the most comprehensive data were included. If an older publication contained more comprehensive data than a more recent one, the more comprehensive study was included. In addition, if an older study contained unique prognostic factor data, then this publication would also be included in the prognostic-factor analysis. Data were extracted from published papers by one reviewer using a standard data-extraction database and then verified independently by a second reviewer. For the meta-analysis, hazard ratios for overall survival and 95\% confidence intervals (CIs) were extracted for each prognostic factor.

\section{Summary of survival data}

The following were identified and summarized for all included studies: median disease-free interval between diagnosis of primary cancer and diagnosis of metastasis; reported 3-, 5-, and 10-year disease-free survival (DFS) rates; and reported 3-, 5-, and 10-year overall survival rates. Wherever possible, survival information was summarized by the following patient subgroups, which were determined a priori to be potentially important determinants of survival (and as reported in the literature): ${ }^{4,15,18}$ (1) isolated CLM (any number); (2) solitary CLM; (3) extrahepatic disease; (4) initially unresectable receiving preoperative chemotherapy; (5) initially resectable; (6) synchronous liver metastases (metastases identified at time of primary CRC diagnosis); and (7) metachronous liver metastases (metastases occurring at a time period defined by study authors after primary CRC diagnosis). All extracted data were based on analyses from the first CLM resection. Median survival rates were calculated for the overall patient population, as well as for patient subgroups with specific prognostic indications.

\section{Median survival}

To calculate a summary value of median survival time, studies that reported information on survival rates only in terms of calendar intervals (eg, 1- or 3-year survival) were converted using a simple interpolation to create a crude median survival time. It was assumed that median survival time fell within reported calendar-specific survival times, and that the survival line between the two time points that crossed the $50 \%$ mark was linear. Summary medians and standard deviations were calculated based on the reported or estimated median values from each individual study.

\section{Trends in survival by prognostic factors}

We assessed the association between survival and seven prognostic factors that previously had been reported in the literature as predictors of survival..$^{2,4,16,17}$ The prognostic factors included number of hepatic metastases, node-positive compared to node-negative primary, poorly differentiated compared to well or moderately primary, extrahepatic disease compared to liver-only disease, tumor diameter, carcinoembryonic antigen (CEA) level, and positive compared 
to negative resection margins. For this study, we set the following cutoff points (cutoffs based on those reported in the original articles) for the following prognostic factors in which categories were required: CEA level $\geq 200$, number of liver metastases $>1$, and tumor diameter $>3 \mathrm{~cm}$. Median survival time for each prognostic factor was plotted by published study dates (1999-2010) separately, and, in addition, was stratified by the seven prognostic factors.

\section{Meta-analysis}

Random-effects meta-analysis models were used to calculate meta-relative risks (mRRs), 95\% CIs, and corresponding $P$-values for heterogeneity for the seven prognostic factors. The presence of significant heterogeneity $(P<0.10)$ indicates that statistical variation between studies in a particular metaanalysis model may invalidate data summaries; ${ }^{19}$ however, lack of statistically significant heterogeneity may not be sufficiently sensitive to indicate underlying variation between studies. Further, a significant test for heterogeneity will not indicate the source of variations among studies. Accordingly, subgroup analyses were conducted by stratifying study size and estimated patient volume per study center (termed "annual clinic volume" herein) to identify potential sources of between-study heterogeneity. The estimated annual clinic volume was calculated as: initial patient population/number of years over which patients were recruited/number of centers participating in the study. Stratifications by study size and annual clinic volume were based on the median number of patients per center $(n=236)$ and median annual clinic volume $(n=21)$ of all studies included in the meta-analysis. We therefore stratified using values of $200(\geq$ and $<$ ) and 20 ( $\geq$ and $<$ ), respectively. To visualize the mRR distribution by annual clinic volume, cumulative meta-analysis plots by each prognostic factor were created, adding each study one at a time from low to high annual clinic volume. Sensitivity analyses were conducted to determine the relative influence that a particular study had on a meta-analysis model. Specifically, the "one study removed" sensitivity analysis was used to assess the relative influence of each study on the model-specific mRR. This was performed by generating an mRR based on all studies, followed by the removal of one study at a time to compare the overall $\mathrm{mRR}$ with $\mathrm{mRR}$ from models with one study removed.

Because study size is likely to be related directly to the annual volume of patients seen at a liver-resection center (eg, $\mathrm{see}^{20}$ ), and with the volume of patients seen annually related to survival, a cumulative meta-analysis based on annual clinic volume size by study center per year (ie, number of patients treated per year per center) was performed. This analysis was conducted to determine whether clinic volume had an impact on overall survival after CLM resection.

We examined the effect of publication bias, examined visually by producing funnel plots that measure the standard error as a function of effect size, as well as performing Begg's adjusted-rank correlation test ${ }^{21}$ and Egger's regression asymmetry test. ${ }^{22}$ All analyses were conducted with the Comprehensive Meta-Analysis (CMA) version 2 (BioStat, Englewood, NJ) statistical package.

\section{Results}

Our initial literature search identified 1493 articles published between 1999 and May 2010. Among these, 1377 articles were excluded because they did not meet inclusion criteria. Of the studies identified, six included in our analyse ${ }^{23-28}$ were also included in the earlier literature review by Simmonds et al, ${ }^{15}$ published in 2006 . A total of 116 articles were identified that reported survival after liver resection in adults with $\mathrm{mCRC}$ and the modifying effect (if any) of other personal and clinical factors on survival. ${ }^{3,4,10-14,16,17,23-127}$ After accounting for overlap of multiple publications reporting on patients from the same center ( 34 articles), our review included a total of approximately 20,745 patients (range: $21-1600$ patients per study). Fifty-four of these studies were included in the meta-analysis. Seventy-five studies (64.7\%) reported median follow-up times of 24-36 months, with the remainder reporting longer follow-up times. Figure 1 provides a diagram illustrating the study selection and exclusion process.

\section{Survival for metastatic colorectal cancer following liver resection}

Ninety-three studies reported overall survival after liver resection in adults with CLM, with varying numbers of studies by patient subgroup (Table 1). Of these, 64 reported 3 -year survival (median 57.5\%, range 29.7\%-80.0\%), 86 studies reported 5-year survival (median 38.0\%, range $16.0 \%-74.0 \%$ ), and 20 studies reported 10 -year overall survival (median 26.0\%, range 9.0\%-69.0\%). Ten studies reported median disease-free interval (median 15.9 months, range 9.2-23.7 months). Twenty-six studies reported 5-year DFS (median $24.7 \%$, range $7.4 \%-48.0 \%$ ), whereas six studies reported 10-year DFS (median 20\%, range 15.0\%-33.7\%). Survival rates stratified by patient subgroups were reported in 27 studies (Table 1); however, no studies reported 10-year survival by subgroup. When evaluating CLM, median survival was highest in patients with solitary CLM, followed by isolated CLM then CLM with extrahepatic disease. Median 


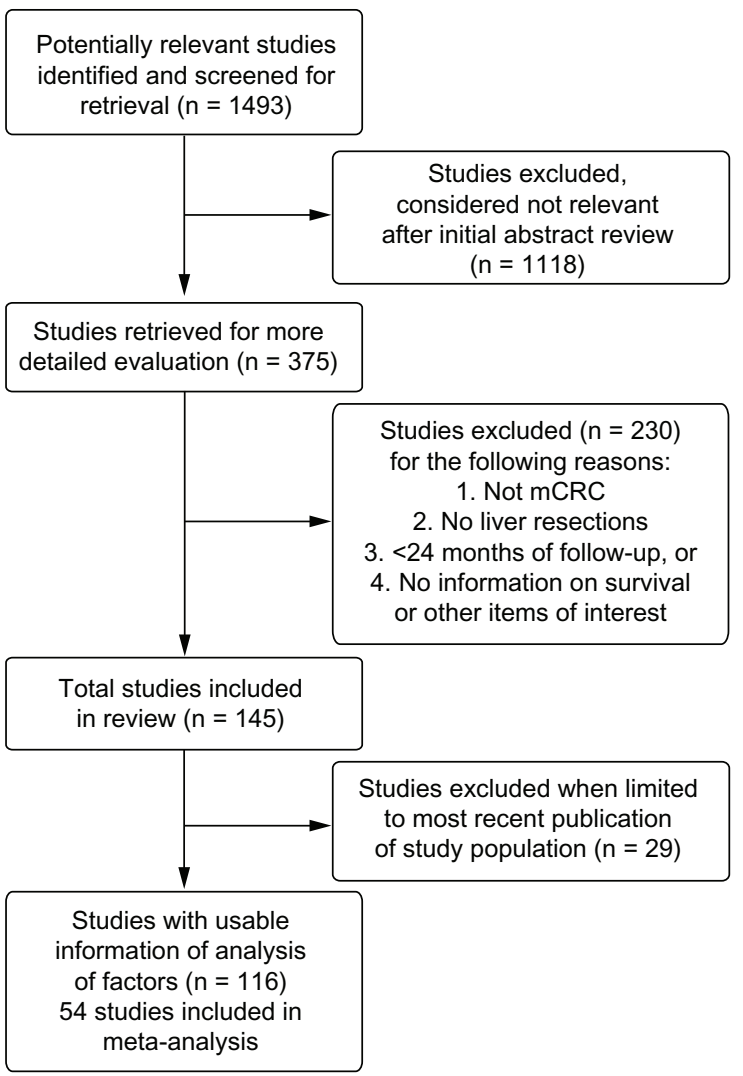

Figure I A diagram illustrating the study selection and exclusion process.

survival was higher in patients with metachronous compared to synchronous disease, though data were limited. Patients receiving preoperative chemotherapy had similar median survival as those patients with initially resectable disease without the need for chemotherapy, though again data were limited.

Sixty-one studies were included in the summary of median survival (Table 1). Of these, median survival times were reported in 41 studies and were estimated for the additional 20 studies that reported survival rates that overlapped $50 \%$ but did not report median survival times. For patients in all 61 studies, the overall summary median of the median survival time was 3.6 (range 1.7-7.3) years. Comparison of median survival by publication date from most recent (2010) to oldest (1999) did not suggest an improvement in median survival in more recent years (data not shown); however, as some of the more recent publications reported survival from patients diagnosed decades earlier, it was not possible to make accurate approximations between publication date and date of treatment and subsequent survival. The median survival varied by the prognostic factor studied (Figure 2). Median survival was better in patients with CEA level $<200$ than in those with CEA level $\geq 200$. In patients with a negative

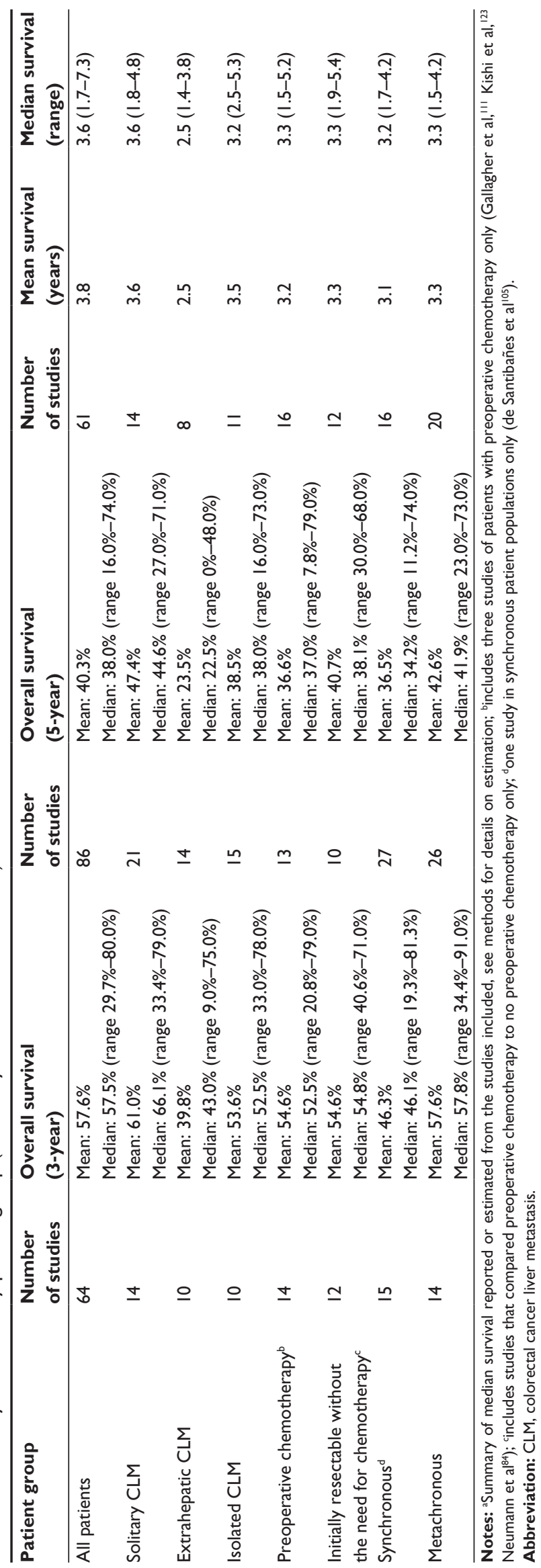




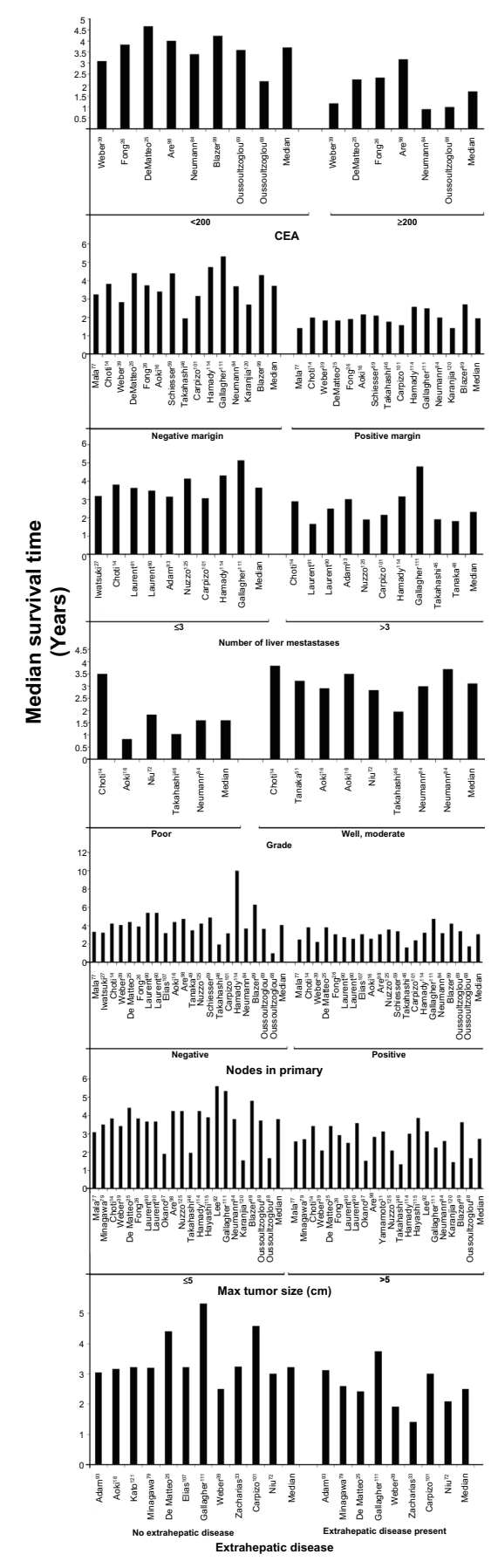

Figure 2 Meta-analysis forest plots of the relative risk and $95 \%$ confidence intervals of survival after liver resection in metastatic colorectal cancer reported in the literature for each of the seven identified prognostic factors.

Abbreviation: CEA, carcinoembryonic antigen.

tumor margin, survival was better than in those with a positive margin, as was survival in patients with fewer than three liver metastases compared to those with at least three liver metastases. Patients with poor grade had poorer median survival than those with good or moderate grade reported, as did those with negative nodes compared to patients with positive nodes (Figure 2).

\section{Meta-analysis}

Risk estimates from multivariate analyses estimating survival were obtained from each study and meta-analyzed for the seven prognostic factors. All prognostic factors were found to be statistically significantly associated with lower survival (Figure 3). Table 2 summarizes the mRRs for each of the prognostic factors overall, by study size and by annual clinic volume. mRRs were elevated for each of the prognostic factors and ranged from the lowest mRR of $1.52(95 \%$ CI, 1.28-1.80) for $\geq 3$-cm tumor diameter to the highest of 2.02 (95\% CI, 1.65-2.48) for positive resection margin. The test for heterogeneity was significant for all our analyses of prognostic factors, except for the analysis of positive primary nodal status $(P=0.55)$. However, all individual studies, with few exceptions, observed elevated hazard ratios for each prognostic factor. Thus, even though statistical heterogeneity was observed, the directionality of the individual studies was virtually uniform. Study characteristics for the 54 studies included in the meta-analysis are shown in Table 3.

Plots for publication bias were created for each of the prognostic factors (results not shown). In general, the plots showed symmetry around the plotted summary log-relative risk, suggesting that publication bias was not large and was unlikely to drive the conclusions; however, all of the loghazard ratios were greater than zero, with few studies reporting null or protective estimates for the prognostic factors.

Stratification by study size of 200 study subjects or fewer and stratification by annual clinic volume ( $<20$ vs $\geq 20$ patients) resulted in marked differences in mRRs for some of the prognostic factors (CEA level, extrahepatic disease, tumor grade and positive resection margin). Each prognostic factor listed in Table 2 was associated with stronger mRRs in studies of greater than 200 subjects (vs < 200) and in studies of annual volume per study center of 20 or more patients (vs $<20$ ), with the exception of $1+$ liver metastases in the clinic volume analysis. Cumulative meta-analyses generally indicated better prognosis by annual clinic volume within the categories of prognostic factors analyzed for positive resection margin, extrahepatic disease, CEA level, tumor diameter, and node-positive status, but this trend was not apparent for $1+$ liver metastases or tumor grade (Figure 4).

\section{Sensitivity analysis}

We conducted several sensitivity analyses to determine the relative impact or influence that each study had on the overall model-specific mRR. For CEA level, one study ${ }^{96}$ had a very different point estimate and CI from the other studies, but contributed only $<1 \%$ of the relative weight; therefore, 


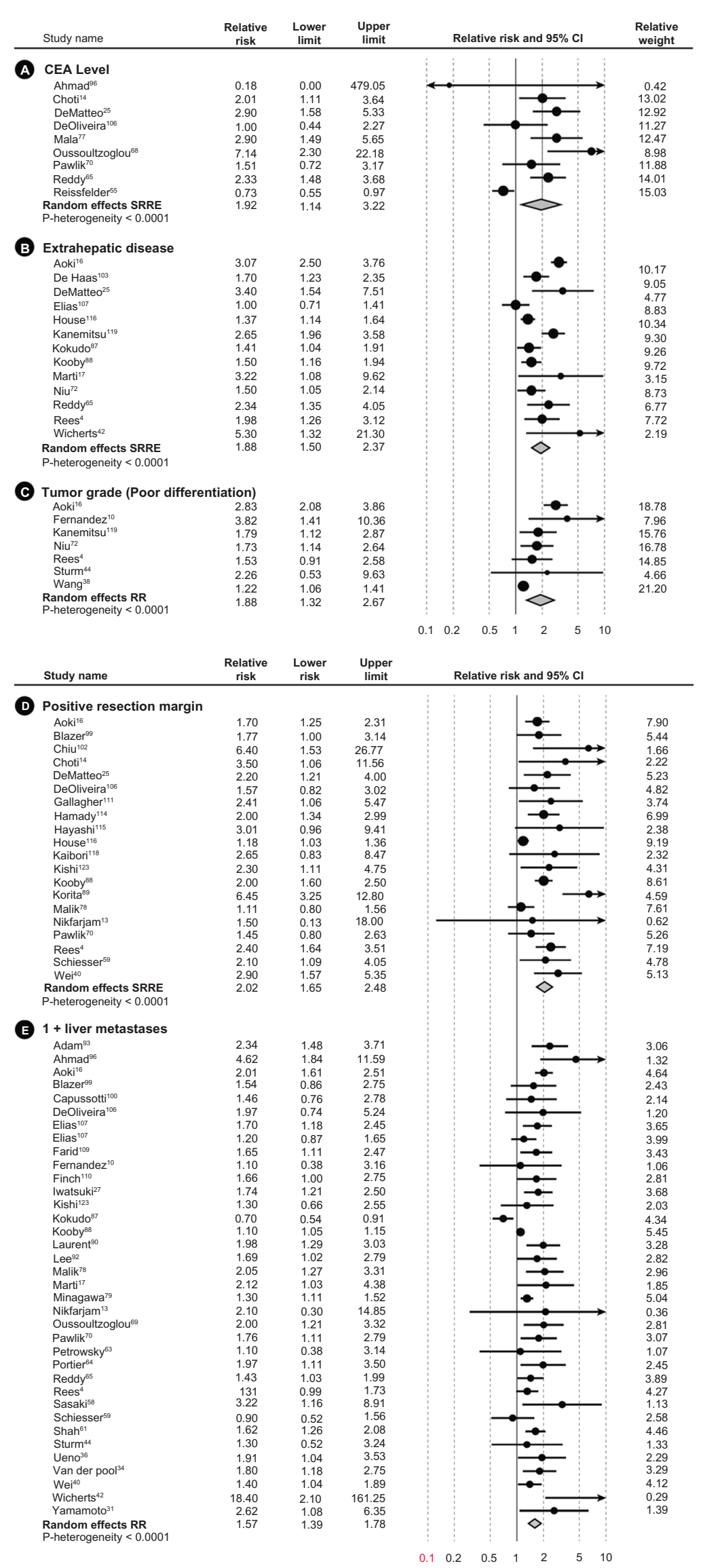

Figure 3 (Continued) 


\begin{tabular}{|c|c|c|c|c|c|}
\hline Study name & $\begin{array}{c}\begin{array}{c}\text { Relative } \\
\text { risk }\end{array} \\
\end{array}$ & $\begin{array}{l}\text { Lower } \\
\text { limit }\end{array}$ & $\begin{array}{l}\text { Upper } \\
\text { limit }\end{array}$ & Relative risk and $95^{\circ}$ & $\begin{array}{c}\text { Relative } \\
\text { weight }\end{array}$ \\
\hline \multicolumn{6}{|l|}{ F Node positive } \\
\hline Ahmad $^{96}$ & 4.47 & & 15.76 & & \\
\hline & 1.76 & 1.33 & 2.32 & & 8.88 \\
\hline Deoliveira 106 & 1.35 & 0.56 & 3.24 & & 0.89 \\
\hline Fernandez & 1.21 & 0.49 & 3.01 & & 0.82 \\
\hline $\begin{array}{l}\text { Finch"10 } \\
\text { Gallagher'111 }\end{array}$ & 1.11 & $\begin{array}{l}0.72 \\
108\end{array}$ & $\begin{array}{l}1.72 \\
5.9\end{array}$ & $t$ & 3.61 \\
\hline $\begin{array}{l}\text { Gallaghere'11" } \\
\text { Hamady'1" }\end{array}$ & $\begin{array}{l}2.43 \\
2.00\end{array}$ & $\begin{array}{l}1.08 \\
1.26\end{array}$ & $\begin{array}{l}5.49 \\
3.19\end{array}$ & & $\begin{array}{l}1.03 \\
3.15\end{array}$ \\
\hline Kooby的 & $\begin{array}{l}2.00 \\
1.50\end{array}$ & 1.26 & 1.79 & & $\begin{array}{r}3.15 \\
22.56\end{array}$ \\
\hline Laurent ${ }^{\circ 0}$ & 1.75 & 1.23 & 2.48 & & 5.57 \\
\hline Lee $^{92}$ & 1.97 & 1.16 & 3.35 & & 2.43 \\
\hline Mala $^{77}$ & 2.10 & 1.16 & 3.79 & & 1.97 \\
\hline Martit7 & 1.74 & 1.00 & 3.03 & & 2.24 \\
\hline Minagawa勇 & 1.50 & 1.27 & 1.77 & - & 25.84 \\
\hline $\begin{array}{l}\text { Nanashimamaic } \\
\text { Nikfarjam }^{13}\end{array}$ & $\begin{array}{l}2.20 \\
2.20\end{array}$ & $\begin{array}{l}0.82 \\
0.21\end{array}$ & $\begin{array}{r}5.94 \\
23.39\end{array}$ & & $\begin{array}{l}0.69 \\
0.12\end{array}$ \\
\hline $\begin{array}{l}\text { Nikfararam }{ }^{23} \\
\text { Rees }^{4}\end{array}$ & $\begin{array}{l}2.20 \\
1.52\end{array}$ & $\begin{array}{l}0.21 \\
122\end{array}$ & 189 & $\rightarrow$ & $\begin{array}{l}0.12 \\
14.28\end{array}$ \\
\hline Schiessers9 & $\begin{array}{l}1.52 \\
1.50\end{array}$ & 0.88 & $\begin{array}{l}1.89 \\
2.55\end{array}$ & 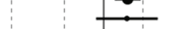 & $\begin{array}{r}14.28 \\
2.43\end{array}$ \\
\hline Sturm ${ }^{44}$ & 0.76 & 0.23 & 2.51 & & 0.48 \\
\hline Ueno ${ }^{36}$ & 1.95 & 1.08 & 3.53 & & 1.96 \\
\hline Yamada $^{29}$ & 4.72 & 1.63 & 13.65 & & 0.61 \\
\hline $\begin{array}{l}\text { Random effects RR } \\
\text { P-heterogeneity }=0.548\end{array}$ & 1.59 & 1.46 & 1.73 & $\Delta$ & \\
\hline \multicolumn{6}{|l|}{ ( ) $>3 \mathrm{~cm}$ tumor diameter } \\
\hline Adam $^{93}$ & 2.40 & 1.31 & 4.40 & & 3.80 \\
\hline $\mathrm{Ahmad}^{96}$ & 0.96 & 0.89 & 1.04 & & 7.19 \\
\hline $\begin{array}{l}\text { Aokitít } \\
\text { Blazerog }\end{array}$ & $\begin{array}{l}2.62 \\
1.33\end{array}$ & $\begin{array}{l}2.23 \\
0.84\end{array}$ & $\begin{array}{l}3.07 \\
2.10\end{array}$ & & $\begin{array}{l}6.86 \\
4.81\end{array}$ \\
\hline De haas ${ }^{103}$ & 1.40 & 1.02 & 1.93 & & 5.81 \\
\hline DeOliveira 106 & 2.09 & 0.67 & 6.54 & & 1.72 \\
\hline 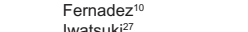 & 1.17 & 0.49 & 2.82 & & 2.49 \\
\hline $\begin{array}{l}\text { Iwatsukiki } \\
\text { Kemeny }{ }^{28}\end{array}$ & $\begin{array}{l}1.49 \\
1.75\end{array}$ & $\begin{array}{l}0.96 \\
0.85\end{array}$ & $\begin{array}{l}2.32 \\
3.60\end{array}$ & 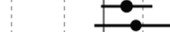 & $\begin{array}{l}4.91 \\
3.18\end{array}$ \\
\hline $\begin{array}{l}\text { Kokudo }{ }^{87} \\
\text { Kokn }\end{array}$ & $\begin{array}{l}1.75 \\
1.75\end{array}$ & $\begin{array}{l}.820 \\
1.24\end{array}$ & 2.47 & & $\begin{array}{l}5.18 \\
5.62\end{array}$ \\
\hline Kooby & 1.00 & 0.95 & 1.05 & & 7.25 \\
\hline Malik ${ }^{78}$ & 1.09 & 0.77 & 1.54 & & 5.62 \\
\hline Martiti & 2.22 & 1.00 & 4.92 & & 2.83 \\
\hline $\mathrm{Ni}^{u^{2}}$ & 1.49 & 1.11 & 2.00 & $\rightarrow$ & 6.00 \\
\hline $\begin{array}{l}\text { Oussoultzoglou } \\
\text { Pawikitio }\end{array}$ & 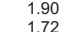 & $\begin{array}{l}1.13 \\
1.14\end{array}$ & $\begin{array}{l}3.19 \\
.59\end{array}$ & & $\begin{array}{l}4.37 \\
514\end{array}$ \\
\hline $\begin{array}{l}\text { Pawlik'10 } \\
\text { Portier }\end{array}$ & 1.72 & 1.14 & $\begin{array}{r}2.59 \\
2.54\end{array}$ & & $\begin{array}{l}5.14 \\
475\end{array}$ \\
\hline Rees $^{4}$ & $\begin{array}{l}1.00 \\
2.03 \\
2\end{array}$ & 1.40 & $\begin{array}{l}2.54 \\
2.94\end{array}$ & & \\
\hline Rees $^{4}$ & 1.20 & 0.92 & 1.56 & & 6.23 \\
\hline Weitio & 1.50 & 1.11 & 2.02 & $\rightarrow$ & 5.97 \\
\hline $\begin{array}{l}\text { Random effects RR } \\
\text { P-shetergoeneity }\end{array}$ & 1.52 & 1.28 & 1.80 & & \\
\hline
\end{tabular}

Figure 3 Summary of median survival after liver resection for metastatic colorectal cancer reported or estimated from the studies included. Note: Results are shown by date of publication as well as the seven identified prognostic factors.

Abbreviations: $\mathrm{CEA}$, carcinoembryonic antigen; $\mathrm{Cl}$, confidence interval.

keeping or removing this study did not appreciably change the mRR for CEA level. In the studies reporting extrahepatic disease, one study ${ }^{107}$ also reported metastases to the lung; however, no effect was seen on the mRR when this study was removed from the analysis. Overall, the meta-analysis models were generally robust to study removal and replacement, indicating little appreciable influence at the individual study level.

\section{Discussion}

Observed median 5-year survival after liver resections for CLM in this review was 38\% (range 16\%-74\%), compared to $30 \%$ (range $15 \%-67 \%$ ) reported in an earlier review of studies published before 2001. ${ }^{15}$ After resection of CLM, median 5 - and 10 -year survival rates were $38 \%$ and $26 \%$, respectively. Comparison of change in median survival over study time period did not show a trend of increasing survival, and this was also true when looking at the prognostic factors individually. Some of the more recent publications included in this review reported survival from patients diagnosed decades earlier; therefore, it may not be possible to make accurate approximations between publication date and date of treatment and subsequent survival. It may also be difficult to show trends in survival given the increasing role of surgical intervention in CLM. ${ }^{2,128,129}$ In addition, more complicated cases such as patients with multiple metastases or extrahepatic disease are now considered standard surgical candidates. ${ }^{2,128,129}$ Inclusion of complicated cases may improve survival on a patient-bypatient basis, although the incremental gain across a larger patient population with a wider range of patient severity may not yet be observed when those with more severe disease are included. ${ }^{128}$ The instrumentation to evaluate the degree of hepatic involvement and surgical technique has also improved, allowing surgeons to make more informed decisions when selecting surgical candidates. ${ }^{2,128}$

All the $\mathrm{mRRs}$ for the prognostic factors reviewed and metaanalyzed were statistically significantly associated with poorer survival. All seven factors exceeded unity on the forest plots (Figure 3). Significant heterogeneity was observed for all but one prognostic factor, which may be partially attributable to variation in clinic volume or study center size, patient selection, or clinical parameters. Our cumulative meta-analyses by annual clinic volume suggested improved survival with increasing clinic volume for each prognostic factor, consistent with observations by others. ${ }^{128}$ Associations for the prognostic factors were stronger in magnitude among studies of 200 or more subjects (vs < 200) and among studies of annual clinic volume of 20 or more patients (vs $<20$ ). 


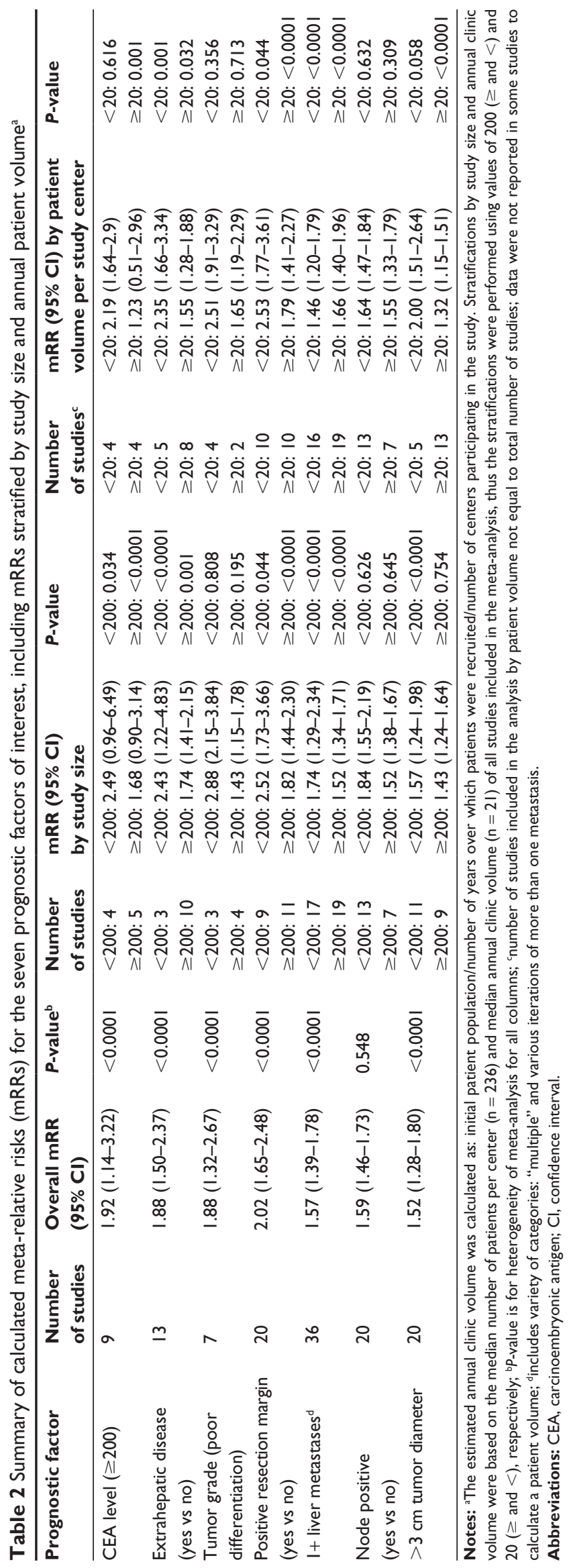

Long-term survival of all patients with mCRC, both operable and inoperable, has been improving significantly over the last two decades. ${ }^{121,130,131}$ Increased use of liver resection has played some part in these improving outcomes, but wide variations in its use persist. ${ }^{130}$ Still, for the approximately $20 \%$ of patients with liver-limited metastases whose disease is determined to be resectable, ${ }^{132}$ hepatectomy with curative intent is now the standard of care. To be more clinically useful, long-term survival after liver resection for mCRC should report 10-year survival. Of the 93 studies we identified that reported survival, only 20 (22\%) reported 10 -year survival rates, whereas the majority reported 3- or 5-year survival. Throughout the 1990s, if studies reported long-term survival, these outcomes consistently examined 3- or 5-year diseasefree and/or overall survival; however, disease can still recur, ${ }^{133}$ and in line with our results, published results show $40 \%$ survival after 5 years posthepatectomy, and slightly less than $30 \%$ after 10 years. Therefore, disease will recur in $70 \%$ of patients following CLM, with the majority in the first 2 years but continuing to occur up to 10 years after such surgery.

Several confounders need to be considered when evaluating survival after resection of CLM. Patient characteristics may play a role, and advanced age has been considered a barrier to offering liver resection. ${ }^{26}$ The issue of patient selection has already been discussed, where surgical intervention is now offered to patients presenting with multiple metastases, large tumor size, and extrahepatic or other underlying liver disease..$^{2,128}$ Recent data ${ }^{134,135}$ from large single centers and international registries demonstrate an association of disease-free and overall survival in older patients with higher operative mortality $(4.7 \%$ for those over 70 , compared to $1.2 \%$ for those under 70 ); however, subsequent disease-free and overall survival are the same, regardless of age.

When analyzing resection data over the study period, the definition of surgical resectability of CLM is not always defined. In the late 1990s, such surgery was offered only to patients with liver-limited disease that was (1) ideally detected metachronously after a previous potentially curative resection of the primary tumor; (2) confined to only one lobe of the liver; (3) showed no more than three metastases, the largest of which was no greater than $5 \mathrm{~cm}$ in diameter; or (4) could be resected on intention to treat with at least a $>1 \mathrm{~cm}$ margin of healthy liver tissue. ${ }^{8,136}$ Based on these criteria, the option of liver surgery would be restricted to the small portion $(<10 \%)^{136}$ of all patients with liver-limited disease. At present, the definition of resectability is disease within the liver, even in the presence of resectable extrahepatic disease, that can be resected, leaving two disease-free 


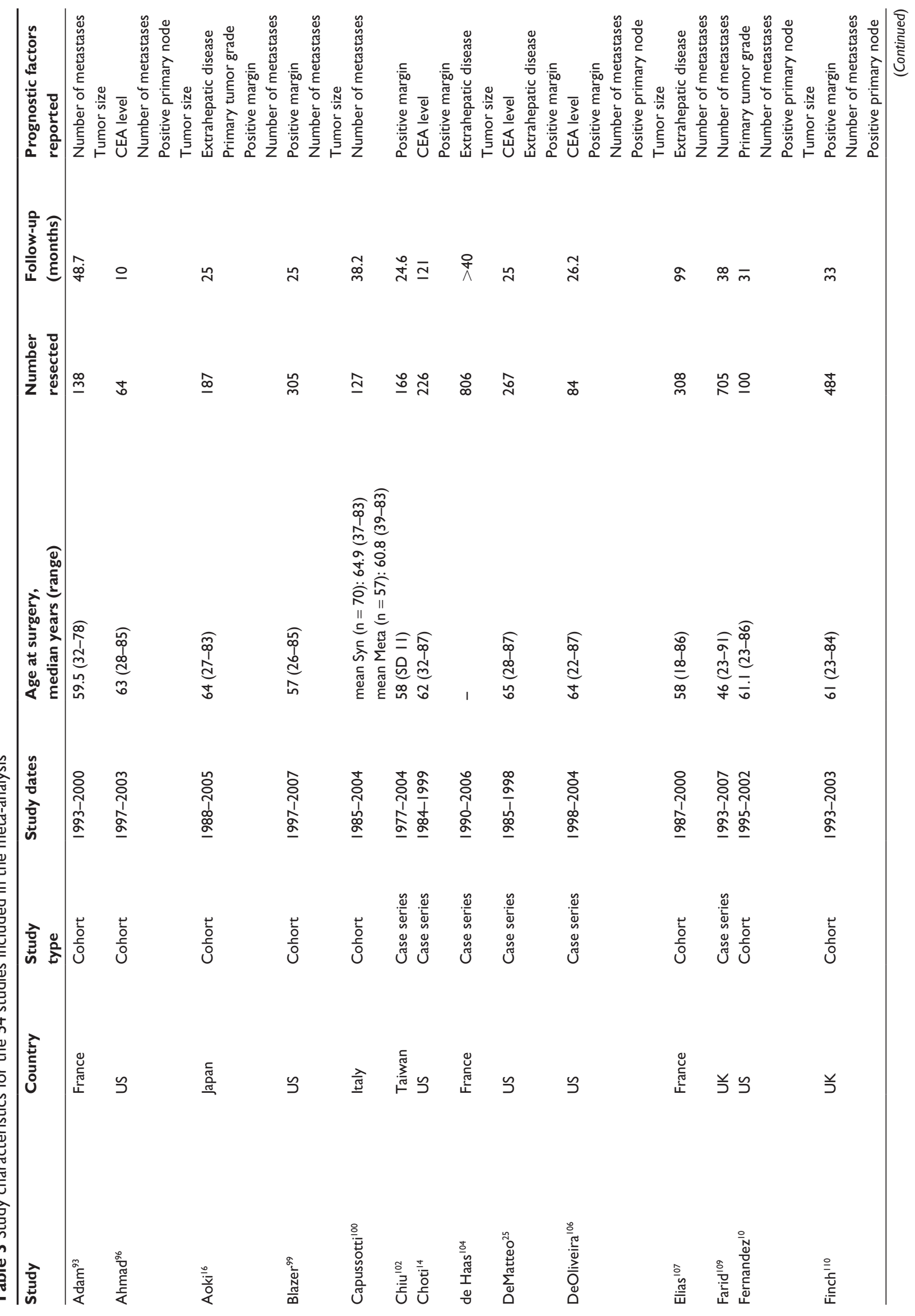




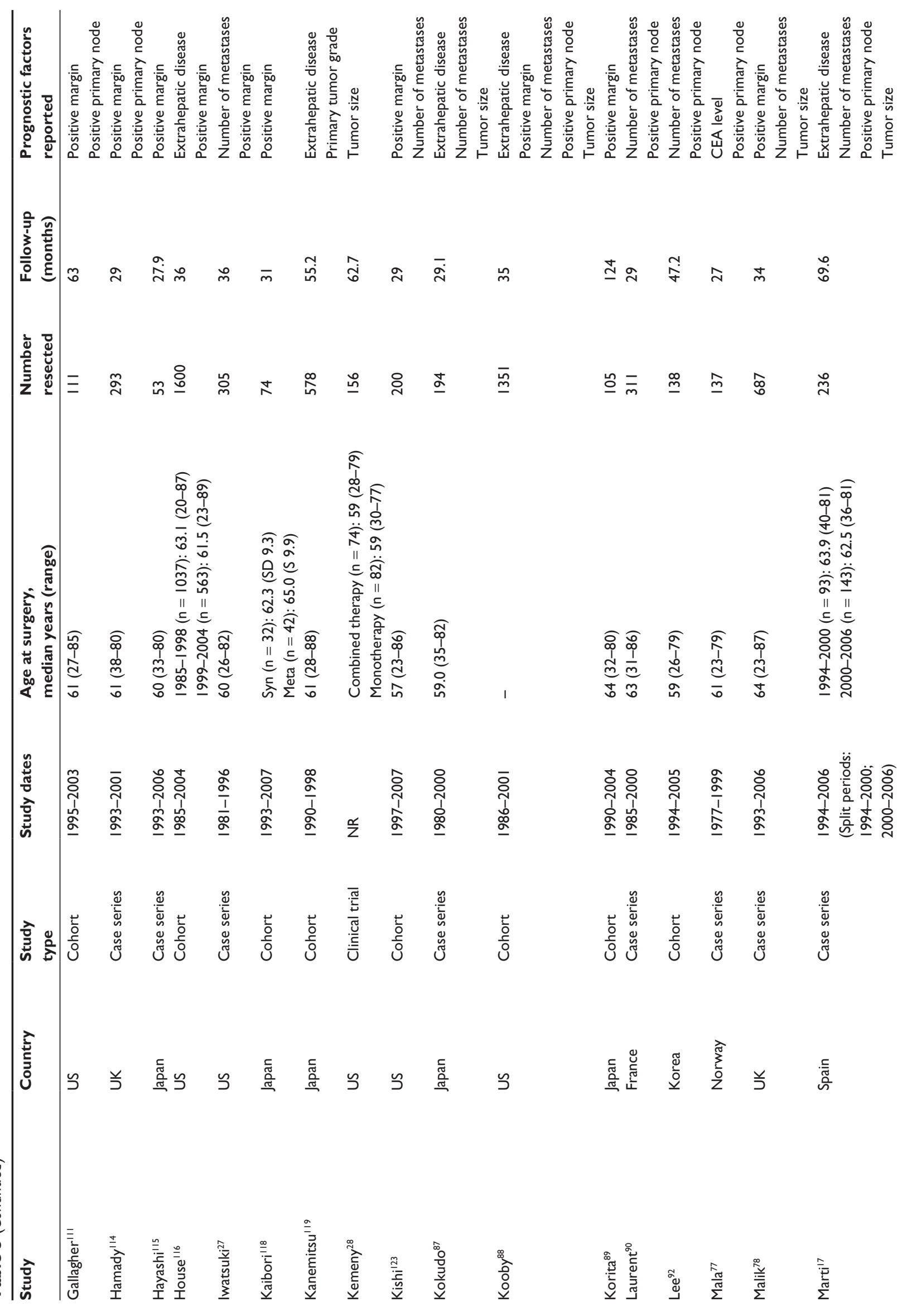




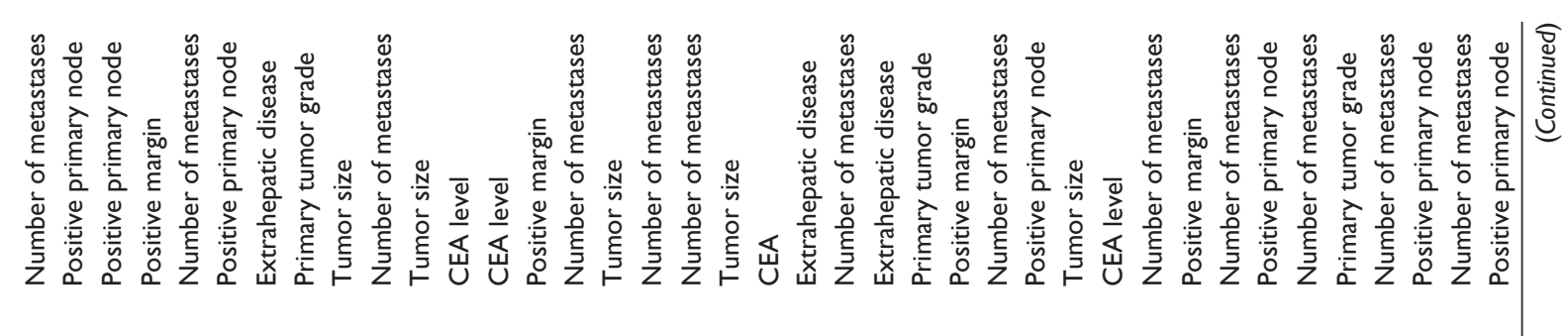

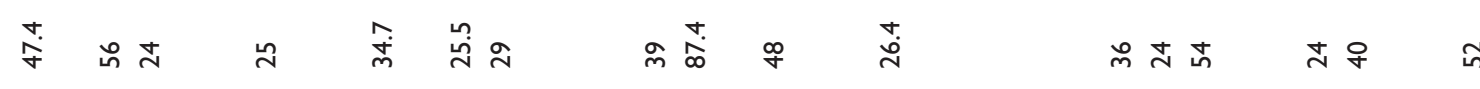

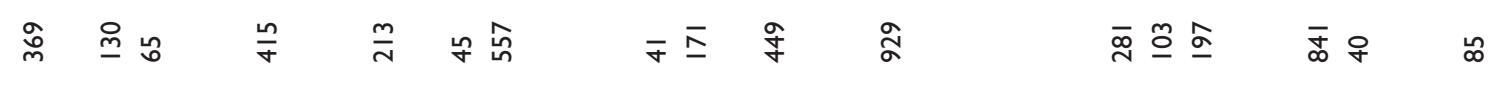

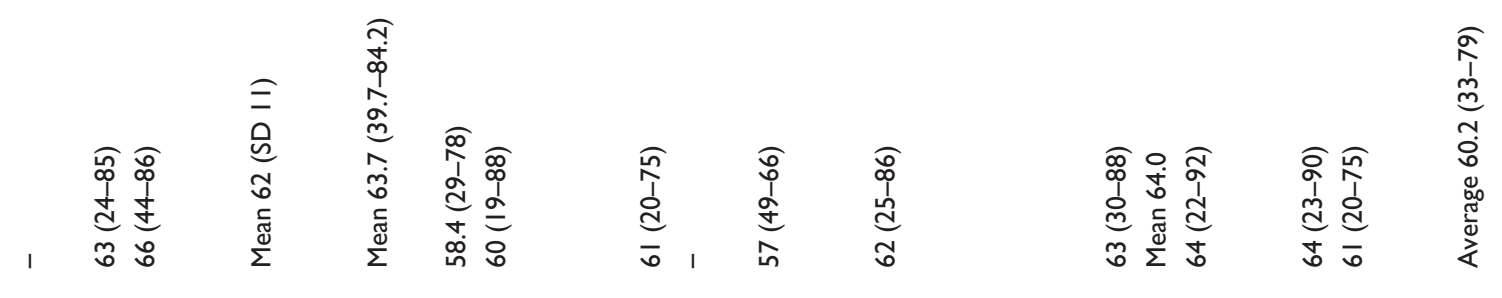

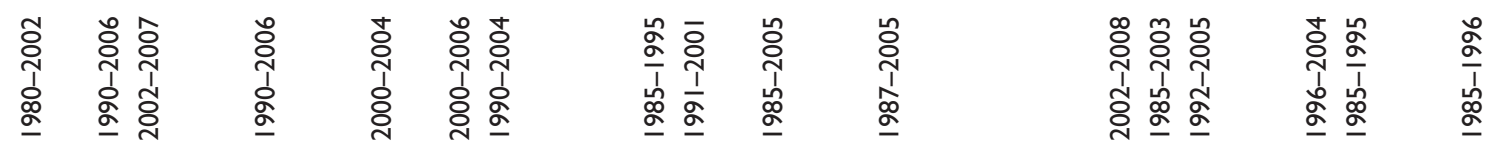

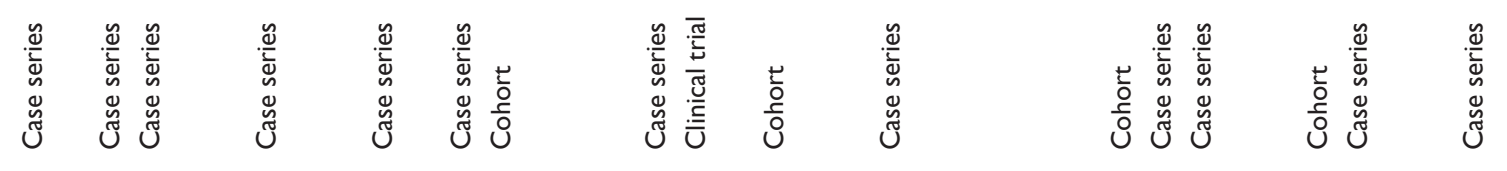

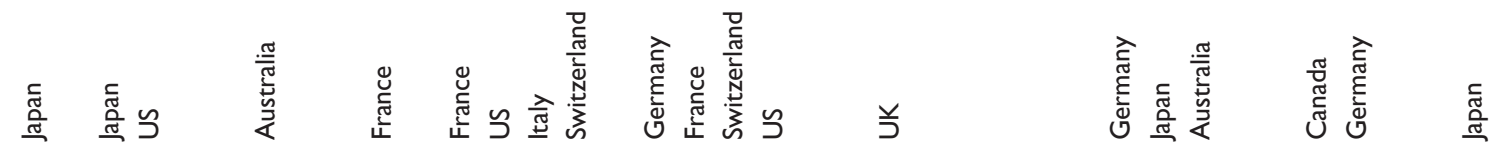

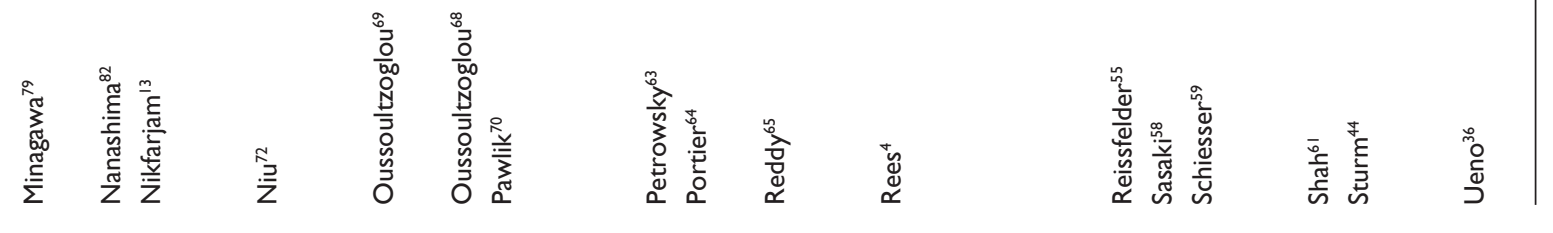




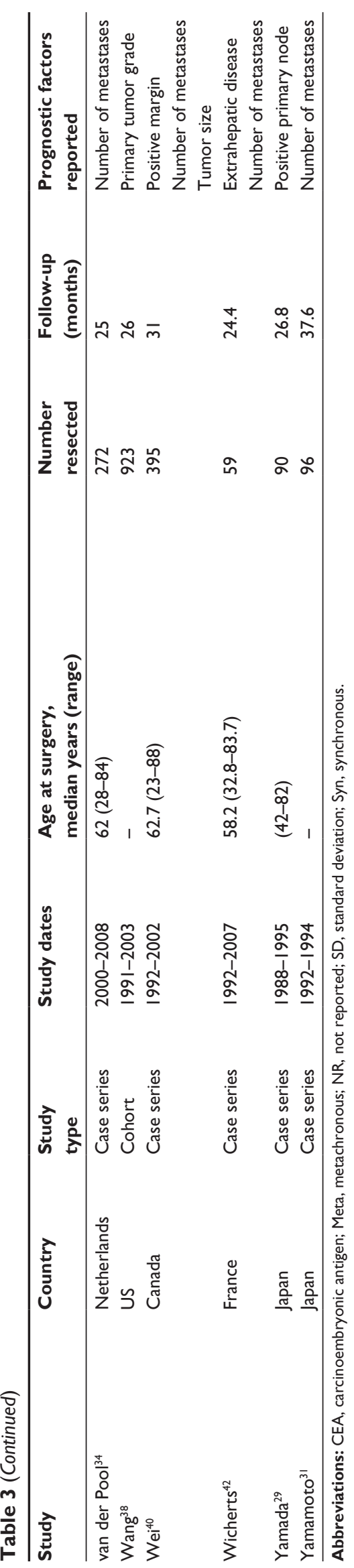

viable contiguous liver segments with a future liver remnant volume of at least $25 \%-30 \%$ and with a viable vascular inflow and viable biliary and vascular outflow. ${ }^{131}$ This new definition of resectability means that at least $20 \%$ of patients with liver-limited disease can now be considered candidates for surgery with long-term survival. It is clear from our analyses that many of the patients who now fulfill the new criteria for such liver surgery also fall into those high-risk prognostic factor groups that are associated with poorer outcomes. As noted above, this observation may partially explain why no definitive overall improvement in survival over time was seen in the studies evaluated, and is supported by observations by others. ${ }^{2,128}$

There are limitations in this review. Our meta-analyses were limited by the availability of risk estimates for the prognostic factors of interest. Multivariate model results were reported inconsistently in studies: some reported only significant factors, others reported all factors, and model covariates usually were not reported. Studies varied by the number of prognostic factors reported in their multivariate analyses, thus we were unable to address the risk for patients with more than one of the prognostic factors in multivariate modeling. Our analysis suggested that publication bias, examined visually by producing funnel plots measuring the standard error as a function of effect size, as well as performing Begg's adjusted-rank correlation test ${ }^{21}$ and Egger's regression asymmetry test ${ }^{22}$ was likely not a factor in our analysis. Due to the missing information in several studies of prognostic factors that were not statistically significant, reporting bias by the study authors may have influenced the calculated summary risk estimates. If there was a reporting bias, however, it would likely result in attenuation of the mRR. Due to the missing information in several studies of prognostic factors that were not statistically significant, reporting bias by the study authors may have influenced the calculated summary risk estimates. If there was a reporting bias, however, it would also likely result in attenuation of the mRR. In calculating the estimated annual clinic volume, we assumed that each center had uniform patient accrual. Referral bias to specialized study centers or selection bias of patients in certain study populations may also have influenced associations, although we were not able to account for these potential limitations based on the available data. ${ }^{128,129}$ Among the studies we included, there was a wide range of 5- and 10-year survival reported. This is, in part, due to the number of articles included (total of 86 studies for 5 -year survival and 20 for 10 -year survival). The wide range also likely reflects differences in study design of the 
Study name

Point estimate

Cumulative relative risk $(95 \% \mathrm{Cl})$

A Positive resection margin:

cumulative meta-analysis by volume (low to high)

Hayashi $^{115}$

Kchiesser $^{59}$

Kaibori'
Chiu'102

Korita ${ }^{89}$

Nikfarjam $^{13}$

Gallagher
Pawlik $^{70}$

Gallagh
Pawlik
Aoki' ${ }^{70}$
Choti 14

Choti ${ }^{14}$

DeOliveira ${ }^{106}$

Blazer ${ }^{99}$

Kishimady ${ }^{123}$

Weiate

Malik $^{78}$

DeMatteo $^{25}$

House ${ }^{116}$

Kooby ${ }^{88}$

$\begin{array}{lll}3.01 & 0.96 & 9.41 \\ 2.30 & 1.30 & 4.06 \\ 2.36 & 1.42 & 3.94 \\ 2.64 & 1.63 & 4.28 \\ 3.58 & 2.12 & 6.07 \\ 3.47 & 2.13 & 5.65 \\ 3.24 & 2.16 & 4.88 \\ 2.76 & 1.78 & 4.29 \\ 2.48 & 1.70 & 3.62 \\ 2.53 & 1.77 & 3.61 \\ 2.37 & 1.72 & 3.26 \\ 2.26 & 1.70 & 3.00 \\ 2.24 & 1.73 & 2.90 \\ 2.18 & 1.75 & 2.72 \\ 2.23 & 1.80 & 2.75 \\ 2.13 & 1.71 & 2.64 \\ 2.23 & 1.85 & 2.69 \\ 2.12 & 1.73 & 2.60 \\ 2.04 & 1.64 & 2.55 \\ 2.02 & 1.65 & 2.48 \\ 2.02 & 1.65 & 2.48\end{array}$

B Extrahepatic disease:

cumulative meta-analysis by volume (low to high)

Kanemitsu'119

Reddy ${ }^{65}$

Kokudo
Aokit

Marti $^{17}$

Elias

$\mathrm{Niu}^{72}$

Rees $^{4}{ }^{403}$

Wicherts ${ }^{42}$

DeMatteo

House ${ }^{116}$

$\begin{array}{lll}2.65 & 1.96 & 3.58 \\ 2.58 & 1.98 & 3.35 \\ 2.03 & 1.31 & 3.17\end{array}$

2.29

2.29
2.35
2.02

$2.02-1.34$

1.57
1.66
1.34
1.34

$\begin{array}{ll}1.89 & 1.38 \\ 1.90 & 1.43\end{array}$

$\begin{array}{ll}2.03 & 1.55 \\ 1.94 & 1.51\end{array}$

1.55
1.51
1.50
1.50

2.50
2.37
1.30

C CEA: cumulative meta-analysis by volume (low to high)

$\mathrm{Mala}^{77}$

Pawlik ${ }^{70}$

Reddy ${ }^{65}$

Choti ${ }^{14}$

DeOliveira $^{10}$

Reissfelder

DeMatteo $^{25}$

$\begin{array}{lll}2.18 & 1.75 & 2.72 \\ 2.23 & 1.80 & 2.75 \\ 2.13 & 1.71 & 2.64 \\ 2.23 & 1.85 & 2.69 \\ 2.12 & 1.73 & 2.60 \\ 2.04 & 1.64 & 2.55 \\ 2.02 & 1.65 & 2.48 \\ 2.02 & 1.65 & 2.48 \\ 2.02 & 1.65 & 2.48\end{array}$

2.72
2.75
2.64
2.69
2.60
2.55
2.48
2.48
2.48

.72
2.75
2.64
2.69
2.60
2.55
2.48
2.48
2.48

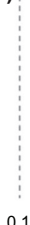

0.1

Study name

Point estimate

Cumulative relative risk $(95 \% \mathrm{Cl})$

D Tumor diameter:

cumulative meta-analysis by volume (low to high)

Kokudo $^{87}$

Pawlik
Fernandez

Aoki ${ }^{16}$

Marti'

Iwatsuki ${ }^{27}$
DeOliveira'

$\mathrm{Niu}^{72}$

Blazere

Ahmad
Weito

Oussoultzoglou ${ }^{68}$

De Haas ${ }^{104}$

Rees $^{4} 5-10 \mathrm{~cm}$

Rees $^{4}>10 \mathrm{~cm}$

Malik ${ }^{70}$

Kooby
Adam $^{93}$

$\begin{array}{lll}1.75 & 1.24 & 2.47 \\ 1.74 & 1.33 & 2.26 \\ 1.68 & 1.30 & 2.17 \\ 1.95 & 1.41 & 2.68 \\ 2.00 & 1.51 & 2.64 \\ 1.89 & 1.45 & 2.46 \\ 1.91 & 2.49 & 2.44 \\ 1.81 & 1.48 & 2.31 \\ 1.75 & 1.39 & 2.20 \\ 1.60 & 1.11 & 2.29 \\ 1.58 & 1.15 & 2.19 \\ 1.61 & 1.18 & 2.19 \\ 1.59 & 1.20 & 2.11 \\ 1.55 & 1.20 & 2.00 \\ 1.58 & 1.23 & 2.02 \\ 1.54 & 1.22 & 1.94 \\ 1.48 & 1.23 & 1.77 \\ 1.51 & 1.26 & 1.80 \\ 1.51 & 1.26 & 1.80\end{array}$

E Node positive:

cumulative meta-analysis by volume (low to high)

Schiesser ${ }^{59}$

Mala ${ }^{77}$

Nanashima ${ }^{82}$

Sturm ${ }^{44}$

Nikfarjam $^{13}$

Yamada $^{29}$

Gallagher ${ }^{111}$

Fernande $z^{10}$

Aoki ${ }^{16}$

Minagawa ${ }^{79}$

Martit7

DeOliveira $^{106}$

Lee $^{92}$

Hamady ${ }^{114}$

Ahmad $^{96}$

Finch 10

Rees $^{4}$
Kooby $^{88}$

\begin{tabular}{llr}
\multicolumn{4}{c}{ y volume (low } & to high) \\
1.50 & 0.88 & 2.55 \\
1.74 & 1.18 & 2.59 \\
1.81 & 1.30 & 2.51 \\
1.84 & 1.35 & 2.51 \\
1.74 & 1.29 & 2.35 \\
1.75 & 1.30 & 2.36 \\
1.88 & 1.41 & 2.51 \\
1.93 & 1.47 & 2.54 \\
1.86 & 1.43 & 2.41 \\
1.81 & 1.50 & 2.19 \\
1.63 & 1.44 & 1.84 \\
1.63 & 1.45 & 1.84 \\
1.64 & 1.47 & 1.84 \\
1.64 & 1.46 & 1.83 \\
1.65 & 1.48 & 1.84 \\
1.67 & 1.50 & 1.86 \\
1.68 & 1.51 & 1.87 \\
1.64 & 1.48 & 1.82 \\
1.62 & 1.47 & 1.78 \\
1.59 & 1.46 & 1.73 \\
1.59 & 1.46 & 1.73 \\
& &
\end{tabular}

2.47
2.26
2.17
2.68
2.64
2.46
2.44
2.31
2.20
2.29
2.19
2.19
2.11
2.00
2.02
1.94
1.77
1.80
1.80



gh)
2.55
2.59
2.51
2.51
2.35
2.36
2.51
2.54
2.41
2.19
1.84
1.84
1.84
1.83
1.84
1.86
1.87
1.82
1.78
1.73
1.73

Cum

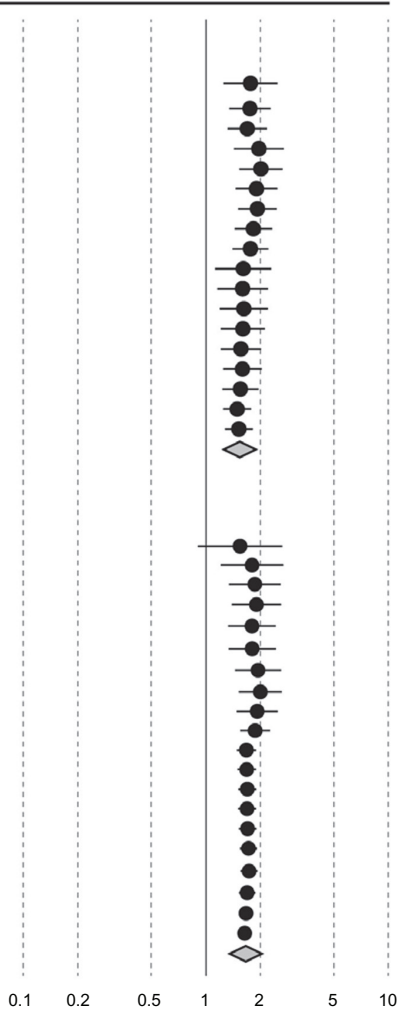

Figure 4 (Continued) 


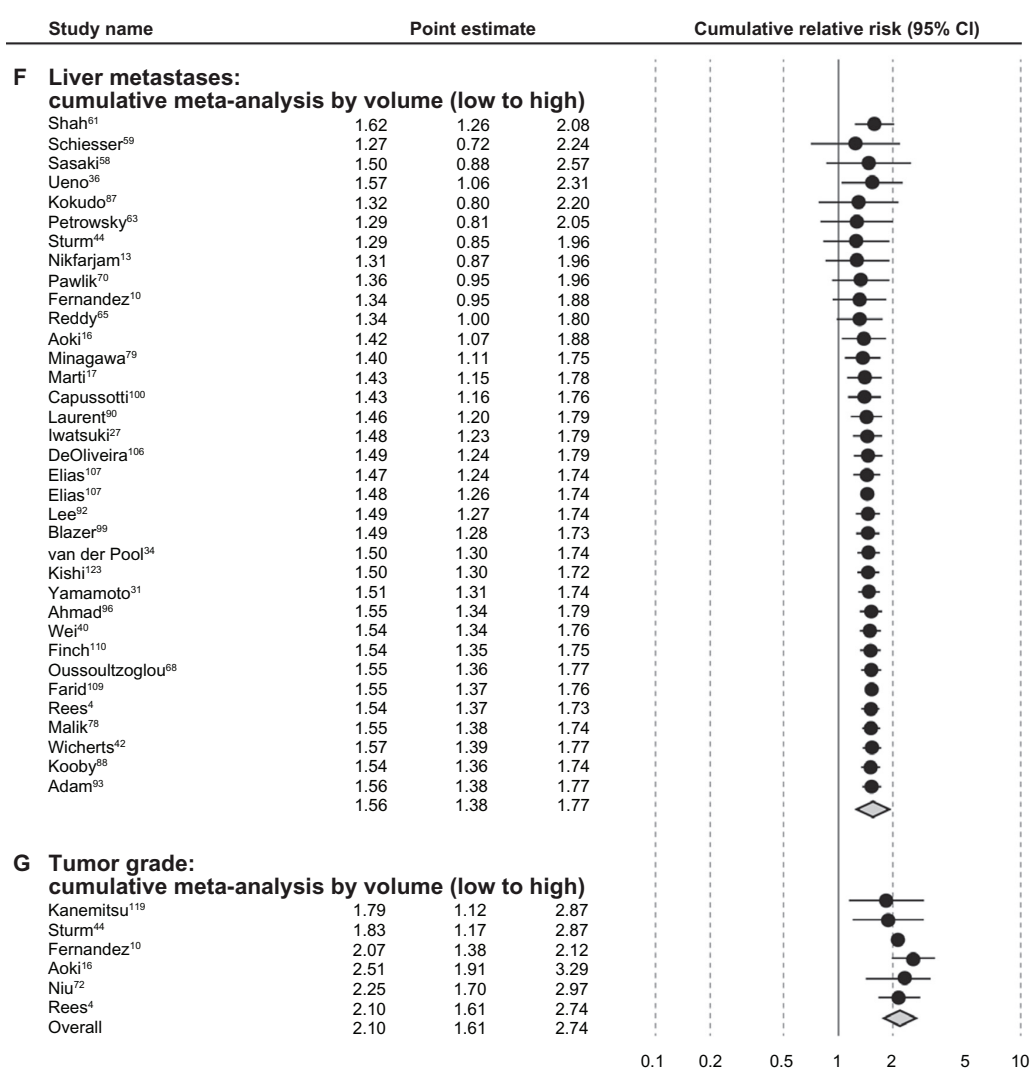

Figure 4 Cumulative meta-analysis of meta relative risks by patient volume and seven prognostic factors identified. Abbreviations: CEA, carcinoembryonic antigen; $\mathrm{Cl}$, confidence interval.

included articles and differences in follow-up period and patient-selection criteria. Overall, this systematic review has shown that the 5-year survival rate following CLM resection in patients with mCRC was approximately $38 \%$. Only $22 \%$ of the studies we included reported 10 -year survival, thus our conclusions regarding 10-year survival following CLM resection are limited. In the future, as follow-up time is accrued among CLM resection patients, we expect that 10 -year survival results will be published to aid in evaluating long-term survival in patients undergoing CLM resection.

\section{Conclusion}

The overall median survival in mCRC patients following CLM liver resection was 3.6 years. All seven investigated prognostic factors showed a modest but significant predictive relationship with survival. In addition, certain prognostic factors may prove useful in clinical practice when assessing optimal therapeutic options.

\section{Acknowledgments}

The authors thank Libby Morimoto, Jaspreet Gujral, Diem HaMai, Nyree Bekerian, and Christine Cappa for their help abstracting data. The authors also thank Gareth Worthington, who is an Amgen employee, for his aid in reviewing and editing the manuscript.

\section{Disclosure}

This study was funded by Amgen. Part of this paper was presented at European Society for Medical Oncology 2010 and World Congress on Gastrointestinal Cancer 2011.

\section{References}

1. Abdalla EK, Adam R, Bilchik AJ, Jaeck D, Vauthey JN, Mahvi D. Improving resectability of hepatic colorectal metastases: expert consensus statement. Ann Surg Oncol. 2006;13(10):1271-1280.

2. Donadon M, Ribero D, Morris-Stiff G, Abdalla EK, Vauthey JN. New paradigm in the management of liver-only metastases from colorectal cancer. Gastrointest Cancer Res. 2007;1(1):20-27.

3. Aloia TA, Vauthey JN, Loyer EM, et al. Solitary colorectal liver metastasis: resection determines outcome. Arch Surg. 2006;141(5): 460-466; discussion 466-467.

4. Rees M, Tekkis PP, Welsh FK, O'Rourke T, John TG. Evaluation of long-term survival after hepatic resection for metastatic colorectal cancer: a multifactorial model of 929 patients. Ann Surg. 2008;247(1): $125-135$.

5. Folprecht G, Grothey A, Alberts S, Raab HR, Kohne CH. Neoadjuvant treatment of unresectable colorectal liver metastases: correlation between tumour response and resection rates. Ann Oncol. 2005;16(8):1311-1319.

6. Bismuth H, Adam R, Levi F, et al. Resection of nonresectable liver metastases from colorectal cancer after neoadjuvant chemotherapy. Ann Surg. 1996;224(4):509-520; discussion 520-522. 
7. Garden OJ, Rees M, Poston GJ, et al. Guidelines for resection of colorectal cancer liver metastases. Gut. 2006;55 Suppl 3:iii1-iii8.

8. Stangl R, Altendorf-Hofmann A, Charnley RM, Scheele J. Factors influencing the natural history of colorectal liver metastases. Lancet. 1994;343(8910):1405-1410.

9. Nordlinger B, Van Cutsem E, Gruenberger T, et al. Combination of surgery and chemotherapy and the role of targeted agents in the treatment of patients with colorectal liver metastases: recommendations from an expert panel. Ann Oncol. 2009;20(6):985-992.

10. Fernandez FG, Drebin JA, Linehan DC, Dehdashti F, Siegel BA, Strasberg SM. Five-year survival after resection of hepatic metastases from colorectal cancer in patients screened by positron emission tomography with F-18 fluorodeoxyglucose (FDG-PET). Ann Surg. 2004;240(3):438-447; discussion 447-450.

11. Lee WS, Yun SH, Chun HK, et al. Clinical outcomes of hepatic resection and radiofrequency ablation in patients with solitary colorectal liver metastasis. J Clin Gastroenterol. 2008;42(8):945-949.

12. Lordan JT, Riga A, Worthington TR, Karanjia ND. Early and long-term outcomes of patients undergoing liver resection and diaphragm excision for advanced colorectal liver metastases. Ann R Coll Surg Engl. 2009;91(6):483-488

13. Nikfarjam M, Shereef S, Kimchi ET, et al. Survival outcomes of patients with colorectal liver metastases following hepatic resection or ablation in the era of effective chemotherapy. Ann Surg Oncol. 2009;16(7):1860-1867.

14. Choti MA, Sitzmann JV, Tiburi MF, et al. Trends in long-term survival following liver resection for hepatic colorectal metastases. Ann Surg. 2002;235(6):759-766

15. Simmonds PC, Primrose JN, Colquitt JL, Garden OJ, Poston GJ, Rees M. Surgical resection of hepatic metastases from colorectal cancer: a systematic review of published studies. Br J Cancer. 2006;94(7):982-999.

16. Aoki T, Umekita N, Tanaka S, Noda K, Warabi M, Kitamura M. Prognostic value of concomitant resection of extrahepatic disease in patients with liver metastases of colorectal origin. Surgery. 2008;143(6):706-714.

17. Marti J, Modolo MM, Fuster J, et al. Prognostic factors and timerelated changes influence results of colorectal liver metastases surgical treatment: a single-center analysis. World J Gastroenterol. 2009;15(21):2587-2594.

18. Adam R, Wicherts DA, de Haas RJ, et al. Patients with initially unresectable colorectal liver metastases: is there a possibility of cure? J Clin Oncol. 2009;27(11):1829-1835.

19. Egger M, Smith GD, Altman DG, editors. Systematic Reviews in Health Care: Meta-analysis in Context. 2nd ed. London: BMJ Publishing Group; 2001.

20. Kopetz S, Chang GJ, Overman MJ, et al. Improved survival in metastatic colorectal cancer is associated with adoption of hepatic resection and improved chemotherapy. J Clin Oncol. 2009;27(22):3677-3683.

21. Dear K, Begg CB. An approach for assessing publication bias prior to performing a meta-analysis. Stat Sci. 1992;7(2):237-245.

22. Egger M, Davey Smith G, Schneider M, Minder C. Bias in meta-analysis detected by a simple, graphical test. BMJ. 1997;315(7109):629-634.

23. Bolton JS, Fuhrman GM. Survival after resection of multiple bilobar hepatic metastases from colorectal carcinoma. Ann Surg. 2000;231(5):743-751.

24. Bradley AL, Chapman WC, Wright JK, et al. Surgical experience with hepatic colorectal metastasis. Am Surg. 1999;65(6):560-566; discussion 566-567.

25. DeMatteo RP, Palese C, Jarnagin WR, Sun RL, Blumgart LH, Fong Y. Anatomic segmental hepatic resection is superior to wedge resection as an oncologic operation for colorectal liver metastases. J Gastrointest Surg. 2000;4(2):178-184.

26. Fong Y, Fortner J, Sun RL, Brennan MF, Blumgart LH. Clinical score for predicting recurrence after hepatic resection for metastatic colorectal cancer: analysis of 1001 consecutive cases. Ann Surg. 1999;230(3):309318; discussion 318-321.
27. Iwatsuki S, Dvorchik I, Madariaga JR, et al. Hepatic resection for metastatic colorectal adenocarcinoma: a proposal of a prognostic scoring system. J Am Coll Surg. 1999;189(3):291-299.

28. Kemeny N, Huang Y, Cohen AM, et al. Hepatic arterial infusion of chemotherapy after resection of hepatic metastases from colorectal cancer. N Engl J Med. 1999;341(27):2039-2048.

29. Yamada H, Katoh H, Kondo S, Okushiba S, Morikawa T. Mesenteric lymph nodes status influencing survival and recurrence pattern after hepatectomy for colorectal liver metastases. Hepatogastroenterology. 2002;49(47):1265-1268.

30. Yamada H, Kondo S, Okushiba S, Morikawa T, Katoh H. Analysis of predictive factors for recurrence after hepatectomy for colorectal liver metastases. World J Surg. 2001;25(9):1129-1133.

31. Yamamoto J, Shimada K, Kosuge T, Yamasaki S, Sakamoto M, Fukuda $\mathrm{H}$. Factors influencing survival of patients undergoing hepatectomy for colorectal metastases. Br J Surg. 1999;86(3):332-337.

32. Yan TD, Chu F, Black D, King DW, Morris DL. Synchronous resection of colorectal primary cancer and liver metastases. World J Surg. 2007;31(7):1496-1501.

33. Zacharias T, Jaeck D, Oussoultzoglou E, Bachellier P, Weber JC. First and repeat resection of colorectal liver metastases in elderly patients. Ann Surg. 2004;240(5):858-865.

34. van der Pool AE, Lalmahomed ZS, de Wilt JH, Eggermont AM, Ijzermans JM, Verhoef C. Local treatment for recurrent colorectal hepatic metastases after partial hepatectomy. J Gastrointest Surg. 2009;13(5):890-895.

35. Tsai MS, Su YH, Ho MC, et al. Clinicopathological features and prognosis in resectable synchronous and metachronous colorectal liver metastasis. Ann Surg Oncol. 2007;14(2):786-794.

36. Ueno H, Mochizuki H, Hatsuse K, Hase K, Yamamoto T. Indicators for treatment strategies of colorectal liver metastases. Ann Surg. 2000; 231(1):59-66.

37. van Etten B, van der Sijp J, Kruyt R, Oudkerk M, van der Holt B, Wiggers T. Ferumoxide-enhanced magnetic resonance imaging techniques in pre-operative assessment for colorectal liver metastases. Eur J Surg Oncol. 2002;28(6):645-651.

38. Wang X, Hershman DL, Abrams JA, et al. Predictors of survival after hepatic resection among patients with colorectal liver metastasis. $\mathrm{Br} \mathrm{J}$ Cancer. 2007;97(12):1606-1612.

39. Weber SM, Jarnagin WR, DeMatteo RP, Blumgart LH, Fong Y. Survival after resection of multiple hepatic colorectal metastases. Ann Surg Oncol. 2000;7(9):643-650.

40. Wei AC, Greig PD, Grant D, Taylor B, Langer B, Gallinger S. Survival after hepatic resection for colorectal metastases: a 10-year experience. Ann Surg Oncol. 2006;13(5):668-676.

41. Welsh FK, Tekkis PP, O'Rourke T, John TG, Rees M. Quantification of risk of a positive (R1) resection margin following hepatic resection for metastatic colorectal cancer: an aid to clinical decision-making. Surg Oncol. 2008;17(1):3-13.

42. Wicherts DA, Miller R, de Haas RJ, et al. Long-term results of twostage hepatectomy for irresectable colorectal cancer liver metastases. Ann Surg. 2008;248(6):994-1005.

43. Strasberg SM, Dehdashti F, Siegel BA, Drebin JA, Linehan D. Survival of patients evaluated by FDG-PET before hepatic resection for metastatic colorectal carcinoma: a prospective database study. Ann Surg. 2001;233(3):293-299.

44. Sturm I, Kohne CH, Wolff G, et al. Analysis of the p53/BAX pathway in colorectal cancer: low BAX is a negative prognostic factor in patients with resected liver metastases. J Clin Oncol. 1999;17(5):1364-1374.

45. Sugawara Y, Yamamoto J, Yamasaki S, Shimada K, Kosuge T, Makuuchi M. Estimating the prognosis of hepatic resection in patients with metastatic liver tumors from colorectal cancer with special concern for the timing of hepatectomy. Surgery. 2001;129(4):408-413.

46. Takahashi S, Konishi M, Nakagohri T, Gotohda N, Saito N, Kinoshita T. Short time to recurrence after hepatic resection correlates with poor prognosis in colorectal hepatic metastasis. Jpn J Clin Oncol. 2006;36(6):368-375. 
47. Tamandl D, Gruenberger B, Herberger B, Kaczirek K, Gruenberger T. Surgery after neoadjuvant chemotherapy for colorectal liver metastases is safe and feasible in elderly patients. J Surg Oncol. 2009;100(5): 364-371.

48. Tanaka K, Shimada H, Matsumoto C, et al. Impact of the degree of liver resection on survival for patients with multiple liver metastases from colorectal cancer. World J Surg. 2008;32(9):2057-2069.

49. Tanaka K, Shimada H, Matsuo K, et al. Outcome after simultaneous colorectal and hepatic resection for colorectal cancer with synchronous metastases. Surgery. 2004;136(3):650-659.

50. Tanaka K, Shimada H, Ueda M, et al. Perioperative complications after hepatectomy with or without intra-arterial chemotherapy for bilobar colorectal cancer liver metastases. Surgery. 2006;139(5):599-607.

51. Tanaka K, Shimada H, Ueda M, Matsuo K, Endo I, Togo S. Long-term characteristics of 5-year survivors after liver resection for colorectal metastases. Ann Surg Oncol. 2007;14(4):1336-1346.

52. Tang AP, Chen J, Padbury R. Long-term survival following liver resection for colorectal metastases - an Adelaide experience. Ann Acad Med Singapore. 2004;33(5 Suppl):S51-S53.

53. Teh CS, Ooi LL. Hepatic resection for colorectal metastases to the liver: The National Cancer Centre/Singapore General Hospital experience. Ann Acad Med Singapore. 2003;32(2):196-204

54. Togo S, Nagano Y, Masui H, et al. Two-stage hepatectomy for multiple bilobular liver metastases from colorectal cancer. Hepatogastroenterology. 2005;52(63):913-919.

55. Reissfelder C, Rahbari NN, Koch M, et al. Validation of prognostic scoring systems for patients undergoing resection of colorectal cancer liver metastases. Ann Surg Oncol. 2009;16(12):3279-3288.

56. Robles R, Marin C, Abellan B, Lopez A, Pastor P, Parrilla P. A new approach to hand-assisted laparoscopic liver surgery. Surg Endosc. 2008;22(11):2357-2364.

57. Sarpel U, Bonavia AS, Grucela A, Roayaie S, Schwartz ME, Labow DM. Does anatomic versus nonanatomic resection affect recurrence and survival in patients undergoing surgery for colorectal liver metastasis? Ann Surg Oncol. 2009;16(2):379-384.

58. Sasaki A, Iwashita Y, Shibata K, Matsumoto T, Ohta M, Kitano S. Analysis of preoperative prognostic factors for long-term survival after hepatic resection of liver metastasis of colorectal carcinoma. J Gastrointest Surg. 2005;9(3):374-380.

59. Schiesser M, Chen JW, Maddern GJ, Padbury RT. Perioperative morbidity affects long-term survival in patients following liver resection for colorectal metastases. J Gastrointest Surg. 2008;12(6):1054-1060.

60. Scoggins CR, Campbell ML, Landry CS, et al. Preoperative chemotherapy does not increase morbidity or mortality of hepatic resection for colorectal cancer metastases. Ann Surg Oncol. 2009;16(1):35-41.

61. Shah SA, Haddad R, Al-Sukhni W, et al. Surgical resection of hepatic and pulmonary metastases from colorectal carcinoma. J Am Coll Surg. 2006;202(3):468-475.

62. Shaw IM, Rees M, Welsh FK, Bygrave S, John TG. Repeat hepatic resection for recurrent colorectal liver metastases is associated with favourable long-term survival. Br J Surg. 2006;93(4):457-464.

63. Petrowsky H, Sturm I, Graubitz O, et al. Relevance of Ki-67 antigen expression and K-ras mutation in colorectal liver metastases. Eur J Surg Oncol. 2001;27(1):80-87.

64. Portier G, Elias D, Bouche O, et al. Multicenter randomized trial of adjuvant fluorouracil and folinic acid compared with surgery alone after resection of colorectal liver metastases: FFCD ACHBTH AURC 9002 trial. J Clin Oncol. 2006;24(31):4976-4982.

65. Reddy SK, Zorzi D, Lum YW, et al. Timing of multimodality therapy for resectable synchronous colorectal liver metastases: a retrospective multi-institutional analysis. Ann Surg Oncol. 2009;16(7): 1809-1819.

66. Noike T, Miwa S, Soeda J, Kobayashi A, Miyagawa S. Increased expression of thioredoxin-1, vascular endothelial growth factor, and redox factor-1 is associated with poor prognosis in patients with liver metastasis from colorectal cancer. Hum Pathol. 2008;39(2): 201-208.
67. Okano K, Maeba T, Moroguchi A, et al. Lymphocytic infiltration surrounding liver metastases from colorectal cancer. J Surg Oncol. 2003;82(1):28-33.

68. Oussoultzoglou E, Romain B, Panaro F, et al. Long-term survival after liver resection for colorectal liver metastases in patients with hepatic pedicle lymph nodes involvement in the era of new chemotherapy regimens. Ann Surg. 2009;249(6):879-886.

69. Oussoultzoglou E, Rosso E, Fuchshuber P, et al. Perioperative carcinoembryonic antigen measurements to predict curability after liver resection for colorectal metastases: a prospective study. Arch Surg. 2008;143(12):1150-1158; discussion 1158-1159.

70. Pawlik TM, Scoggins CR, Zorzi D, et al. Effect of surgical margin status on survival and site of recurrence after hepatic resection for colorectal metastases. Ann Surg. 2005;241(5):715-722; discussion 722-714.

71. Nijkamp MW, van der Bilt JD, Snoeren N, et al. Prolonged portal triad clamping during liver surgery for colorectal liver metastases is associated with decreased time to hepatic tumour recurrence. Eur J Surg Oncol. 2010;36(2):182-188.

72. Niu R, Yan TD, Zhu JC, Black D, Chu F, Morris DL. Recurrence and survival outcomes after hepatic resection with or without cryotherapy for liver metastases from colorectal carcinoma. Ann Surg Oncol. 2007;14(7):2078-2087.

73. Nuzzo G, Giuliante F, Ardito F, et al. Influence of surgical margin on type of recurrence after liver resection for colorectal metastases: a single-center experience. Surgery. 2008;143(3):384-393.

74. Liersch T, Meller J, Bittrich M, Kulle B, Becker H, Goldenberg DM. Update of carcinoembryonic antigen radioimmunotherapy with ${ }^{131}$ I-labetuzumab after salvage resection of colorectal liver metastases: comparison of outcome to a contemporaneous control group. Ann Surg Oncol. 2007;14(9):2577-2590.

75. Liersch T, Meller J, Kulle B, et al. Phase II trial of carcinoembryonic antigen radioimmunotherapy with ${ }^{131}$ I-labetuzumab after salvage resection of colorectal metastases in the liver: five-year safety and efficacy results. J Clin Oncol. 2005;23(27):6763-6770.

76. Lordan JT, Karanjia ND. 'Close shave' in liver resection for colorectal liver metastases. Eur J Surg Oncol. 2010;36(1):47-51.

77. Mala T, Edwin B, Gladhaug I, et al. A comparative study of the shortterm outcome following open and laparoscopic liver resection of colorectal metastases. Surg Endosc. 2002;16(7):1059-1063.

78. Malik HZ, Prasad KR, Halazun KJ, et al. Preoperative prognostic score for predicting survival after hepatic resection for colorectal liver metastases. Ann Surg. 2007;246(5):806-814.

79. Minagawa M, Yamamoto J, Kosuge T, Matsuyama Y, Miyagawa S, Makuuchi M. Simplified staging system for predicting the prognosis of patients with resectable liver metastasis: development and validation. Arch Surg. 2007;142(3):269-276; discussion 277.

80. Moroz P, Salama PR, Gray BN. Resecting large numbers of hepatic colorectal metastases. ANZ J Surg. 2002;72(1):5-10.

81. Mutsaerts EL, van Ruth S, Zoetmulder FA, Rutgers EJ, Hart AA, van Coevorden F. Prognostic factors and evaluation of surgical management of hepatic metastases from colorectal origin: a 10-year single-institute experience. J Gastrointest Surg. 2005;9(2):178-186.

82. Nanashima A, Araki M, Tobinaga S, et al. Relationship between period of survival and clinicopathological characteristics in patients with colorectal liver metastasis. Eur J Surg Oncol. 2009;35(5): 504-509.

83. Neal CP, Mann CD, Sutton CD, et al. Evaluation of the prognostic value of systemic inflammation and socioeconomic deprivation in patients with resectable colorectal liver metastases. Eur J Cancer. 2009;45(1):56-64.

84. Neumann UP, Thelen A, Rocken C, et al. Nonresponse to preoperative chemotherapy does not preclude long-term survival after liver resection in patients with colorectal liver metastases. Surgery. 2009;146(1):52-59.

85. Nicoli N, Casaril A, Mangiante G, Ciola M, Abu Hilal M, Marchiori L. Surgical treatment for liver metastases from colorectal carcinoma: results of 228 patients. Hepatogastroenterology. 2004;51(60):1810-1814. 
86. Koch M, Kienle P, Hinz U, et al. Detection of hematogenous tumor cell dissemination predicts tumor relapse in patients undergoing surgical resection of colorectal liver metastases. Ann Surg. 2005;241(2):199-205.

87. Kokudo N, Miki Y, Sugai S, et al. Genetic and histological assessment of surgical margins in resected liver metastases from colorectal carcinoma: minimum surgical margins for successful resection. Arch Surg. 2002;137(7):833-840.

88. Kooby DA, Stockman J, Ben-Porat L, et al. Influence of transfusions on perioperative and long-term outcome in patients following hepatic resection for colorectal metastases. Ann Surg. 2003;237(6):860-869; discussion 869-870.

89. Korita PV, Wakai T, Shirai Y, et al. Intrahepatic lymphatic invasion independently predicts poor survival and recurrences after hepatectomy in patients with colorectal carcinoma liver metastases. Ann Surg Oncol. 2007;14(12):3472-3480.

90. Laurent C, Sa Cunha A, Couderc P, Rullier E, Saric J. Influence of postoperative morbidity on long-term survival following liver resection for colorectal metastases. Br J Surg. 2003;90(9):1131-1136.

91. Laurent C, Sa Cunha A, Rullier E, Smith D, Rullier A, Saric J. Impact of microscopic hepatic lymph node involvement on survival after resection of colorectal liver metastasis. J Am Coll Surg. 2004;198(6):884-891.

92. Lee WS, Kim MJ, Yun SH, et al. Risk factor stratification after simultaneous liver and colorectal resection for synchronous colorectal metastasis. Langenbecks Arch Surg. 2008;393(1):13-19.

93. Adam R, Delvart V, Pascal G, et al. Rescue surgery for unresectable colorectal liver metastases downstaged by chemotherapy: a model to predict long-term survival. Ann Surg. 2004;240(4):644-657; discussion 657-648.

94. Adam R, Pascal G, Azoulay D, Tanaka K, Castaing D, Bismuth H. Liver resection for colorectal metastases: the third hepatectomy. Ann Surg. 2003;238(6):871-883; discussion 883-874.

95. Adam R, Pascal G, Castaing D, et al. Tumor progression while on chemotherapy: a contraindication to liver resection for multiple colorectal metastases? Ann Surg. 2004;240(6):1052-1061; discussion 1061-1054.

96. Ahmad A, Chen SL, Bilchik AJ. Role of repeated hepatectomy in the multimodal treatment of hepatic colorectal metastases. Arch Surg. 2007;142(6):526-531; discussion 531-522.

97. Andres A, Majno PE, Morel P, et al. Improved long-term outcome of surgery for advanced colorectal liver metastases: reasons and implications for management on the basis of a severity score. Ann Surg Oncol. 2008;15(1):134-143.

98. Are C, Gonen M, Zazzali K, et al. The impact of margins on outcome after hepatic resection for colorectal metastasis. Ann Surg. 2007;246(2):295-300.

99. Blazer DG 3rd, KishiY, Maru DM, et al. Pathologic response to preoperative chemotherapy: a new outcome end point after resection of hepatic colorectal metastases. J Clin Oncol. 2008;26(33):5344-5351.

100. Capussotti L, Vigano L, Ferrero A, Lo Tesoriere R, Ribero D, Polastri R. Timing of resection of liver metastases synchronous to colorectal tumor: proposal of prognosis-based decisional model. Ann Surg Oncol. 2007;14(3):1143-1150

101. Carpizo DR, Are C, Jarnagin W, et al. Liver resection for metastatic colorectal cancer in patients with concurrent extrahepatic disease: results in 127 patients treated at a single center. Ann Surg Oncol. 2009;16(8):2138-2146

102. Chiu CT, Chiang JM, Yeh TS, et al. Clinicopathological analysis of colorectal cancer liver metastasis and intrahepatic cholangiocarcinoma: are they just apples and oranges? Dig Liver Dis. 2008;40(9):749-754.

103. de Haas RJ, Wicherts DA, Flores E, Azoulay D, Castaing D, Adam R. $\mathrm{R} 1$ resection by necessity for colorectal liver metastases: is it still a contraindication to surgery? Ann Surg. 2008;248(4):626-637.

104. de Haas RJ, Wicherts DA, Salloum C, et al. Long-term outcomes after hepatic resection for colorectal metastases in young patients. Cancer. 2010;116(3):647-658.
105. de Santibañes E, Lassalle FB, McCormack L, et al. Simultaneous colorectal and hepatic resections for colorectal cancer: postoperative and longterm outcomes. J Am Coll Surg. 2002;195(2): 196-202

106. DeOliveira ML, Pawlik TM, Gleisner AL, Assumpcaom L, LopesFilho GJ, Choti MA. Echogenic appearance of colorectal liver metastases on intraoperative ultrasonography is associated with survival after hepatic resection. J Gastrointest Surg. 2007;11(8):970-976; discussion 976.

107. Elias D, Liberale G, Vernerey D, et al. Hepatic and extrahepatic colorectal metastases: when resectable, their localization does not matter, but their total number has a prognostic effect. Ann Surg Oncol. 2005;12(11):900-909.

108. Ercolani G, Grazi GL, Ravaioli M, et al. Liver resection for multiple colorectal metastases: influence of parenchymal involvement and total tumor volume, vs number or location, on long-term survival. Arch Surg. 2002;137(10):1187-1192.

109. Farid SG, Aldouri A, Morris-Stiff G, et al. Correlation between postoperative infective complications and long-term outcomes after hepatic resection for colorectal liver metastasis. Ann Surg. 2010;251(1):91-100.

110. Finch RJ, Malik HZ, Hamady ZZ, et al. Effect of type of resection on outcome of hepatic resection for colorectal metastases. Br J Surg. 2007;94(10):1242-1248

111. Gallagher DJ, Zheng J, Capanu M, et al. Response to neoadjuvant chemotherapy does not predict overall survival for patients with synchronous colorectal hepatic metastases. Ann Surg Oncol. 2009;16(7):1844-1851.

112. Giuliante F, Ardito F, Vellone M, et al. Role of the surgeon as a variable in long-term survival after liver resection for colorectal metastases. J Surg Oncol. 2009;100(7):538-545.

113. Halazun KJ, Al-Mukhtar A, Aldouri A, et al. Right hepatic trisectionectomy for hepatobiliary diseases: results and an appraisal of its current role. Ann Surg. 2007;246(6):1065-1074

114. Hamady ZZ, Cameron IC, Wyatt J, Prasad RK, Toogood GJ, Lodge JP. Resection margin in patients undergoing hepatectomy for colorectal liver metastasis: a critical appraisal of the $1 \mathrm{~cm}$ rule. Eur $J$ Surg Oncol. 2006;32(5):557-563.

115. Hayashi H, Nabeshima K, Hamasaki M, Yamashita Y, Shirakusa T, Iwasaki H. Presence of microsatellite lesions with colorectal liver metastases correlate with intrahepatic recurrence after surgical resection. Oncol Rep. 2009;21(3):601-607.

116. House MG, Ito H, Gonen M, et al. Survival after hepatic resection for metastatic colorectal cancer: trends in outcomes for 1,600 patients during two decades at a single institution. J Am Coll Surg. 2010;210(5):744-755.

117. Hur H, Ko YT, Min BS, et al. Comparative study of resection and radiofrequency ablation in the treatment of solitary colorectal liver metastases. Am J Surg. 2009;197(6):728-736.

118. Kaibori M, Iwamoto S, Ishizaki M, et al. Timing of resection for synchronous liver metastases from colorectal cancer. Dig Dis Sci. 2010;55(11):3262-3270.

119. Kanemitsu Y, Kato T. Prognostic models for predicting death after hepatectomy in individuals with hepatic metastases from colorectal cancer. World J Surg. 2008;32(6):1097-1107.

120. Karanjia ND, Lordan JT, Quiney N, Fawcett WJ, Worthington TR, Remington J. A comparison of right and extended right hepatectomy with all other hepatic resections for colorectal liver metastases: a tenyear study. Eur J Surg Oncol. 2009;35(1):65-70.

121. Kato T, Yasui K, Hirai T, et al. Therapeutic results for hepatic metastasis of colorectal cancer with special reference to effectiveness of hepatectomy: analysis of prognostic factors for 763 cases recorded at 18 institutions. Dis Colon Rectum. 2003;46(10 Suppl): S22-S31.

122. Kim SY, Kim HJ, Hong YS, et al. Resected colorectal liver metastases: does the survival differ according to postoperative chemotherapy regimen? J Surg Oncol. 2009;100(8):713-718. 
123. Kishi Y, Kopetz S, Chun YS, Palavecino M, Abdalla EK, Vauthey JN. Blood neutrophil-to-lymphocyte ratio predicts survival in patients with colorectal liver metastases treated with systemic chemotherapy. Ann Surg Oncol. 2009;16(3):614-622.

124. Capussotti L, Muratore A, Mulas MM, Massucco P, Aglietta M. Neoadjuvant chemotherapy and resection for initially irresectable colorectal liver metastases. Br J Surg. 2006;93(8):1001-1006.

125. Nuzzo G, Giuliante F, Ardito F, et al. Liver resection for primarily unresectable colorectal metastases downsized by chemotherapy. J Gastrointest Surg. 2007;11(3):318-324.

126. Pulitano C, Arru M, Catena M, et al. Results of preoperative hepatic arterial infusion chemotherapy in patients undergoing liver resection for colorectal liver metastases. Ann Surg Oncol. 2008;15(6):1661-1669.

127. Lau WY, Lai EC. Hepatic resection for colorectal liver metastases. Singapore Med J. 2007;48(7):635-639.

128. Marshall JL. More fanfare for metastatic colon cancer resections. Gastrointest Cancer Res. 2007;1(1):28.

129. Morris EJ, Forman D, Thomas JD, et al. Surgical management and outcomes of colorectal cancer liver metastases. Br J Surg. 2010;97(7):1110-1118.

130. Lang K, Korn JR, Lee DW, Lines LM, Earle CC, Menzin J. Factors associated with improved survival among older colorectal cancer patients in the US: a population-based analysis. BMC Cancer. 2009;9:227.

131. Vauthey JN, Dixon E, Abdalla EK, et al. Pretreatment assessment of hepatocellular carcinoma: expert consensus statement. HPB (Oxford). 2010;12(5):289-299.

132. Tomlinson JS, Jarnagin WR, DeMatteo RP, et al. Actual 10-year survival after resection of colorectal liver metastases defines cure. J Clin Oncol. 2007;25(29):4575-4580.

133. Adam R, Bhangui P, Poston G, et al. Is perioperative chemotherapy useful for solitary, metachronous, colorectal liver metastases? Ann Surg. 2010;252(5):774-787.

134. de Liguori Carino N, van Leeuwen BL, Ghaneh P, Wu A, Audisio RA, Poston GJ. Liver resection for colorectal liver metastases in older patients. Crit Rev Oncol Hematol. 2008;67(3):273-278.

135. Rees M, Plant G, Bygrave S. Late results justify resection for multiple hepatic metastases from colorectal cancer. Br J Surg. 1997;84(8):1136-1140.

136. Adam R, Haller DG, Poston G, et al. Toward optimized front-line therapeutic strategies in patients with metastatic colorectal cancer an expert review from the International Congress on Anti-Cancer Treatment (ICACT) 2009. Ann Oncol. 2010;21(8):1579-1584.
137. Folprecht G, Gruenberger T, Bechstein WO, et al. Tumour response and secondary resectability of colorectal liver metastases following neoadjuvant chemotherapy with cetuximab: the CELIM randomised phase 2 trial. Lancet Oncol. 2010;11(1):38-47.

138. Van Cutsem E, Kohne CH, Lang I, et al. Cetuximab plus irinotecan, fluorouracil, and leucovorin as first-line treatment for metastatic colorectal cancer: updated analysis of overall survival according to tumor KRAS and BRAF mutation status. $J$ Clin Oncol. 2011;29(15):2011-2019.

139. Lordan JT, Karanjia ND, Quiney N, Fawcett WJ, Worthington TR. A 10-year study of outcome following hepatic resection for colorectal liver metastases - the effect of evaluation in a multidisciplinary team setting. Eur J Surg Oncol. 2009;35(3):302-306.

140. Lorenz M, Müller HH. Randomized, multicenter trial of fluorouracil plus leucovorin administered either via hepatic arterial or intravenous infusion versus fluorodeoxyuridine administered via hepatic arterial infusion in patients with nonresectable liver metastases from colorectal carcinoma. J Clin Oncol. 2000;18(2):243-254.

141. Mitry E, Fields AL, Bleiberg H, et al. Adjuvant chemotherapy after potentially curative resection of metastases from colorectal cancer: a pooled analysis of two randomized trials. J Clin Oncol. 2008;26(30):4906-4911.

142. Nordlinger B, Sorbye H, Glimelius B, et al. Perioperative chemotherapy with FOLFOX4 and surgery versus surgery alone for resectable liver metastases from colorectal cancer (EORTC Intergroup trial 40983): a randomised controlled trial. Lancet. 2008;371(9617):1007-1016.

143. Kemeny MM, Adak S, Gray B, et al. Combined-modality treatment for resectable metastatic colorectal carcinoma to the liver: surgical resection of hepatic metastases in combination with continuous infusion of chemotherapy - an intergroup study. J Clin Oncol. 2002;20(6):1499-1505.

144. Adam R, Frilling A, Elias D, et al. Liver resection of colorectal metastases in elderly patients. Br J Surg. 2010;97(3):366-376.

145. Karanjia ND, Lordan JT, Fawcett WJ, Quiney N, Worthington TR. Survival and recurrence after neo-adjuvant chemotherapy and liver resection for colorectal metastases: a ten year study. Eur J Surg Oncol. 2009;35(8):838-843.

146. Byam J, Reuter NP, Woodall CE, Scoggins CR, McMasters KM, Martin RC. Should hepatic metastatic colorectal cancer patients with extrahepatic disease undergo liver resection/ablation? Ann Surg Oncol. 2009;16(11):3064-3069.

147. Tamandl D, Gruenberger B, Herberger B, et al. Selective resection of colorectal liver metastases. Eur J Surg Oncol. 2007;33(2):174-182. 


\section{Supplementary material \\ Search strategy}

The PubMed literature search included the following query: liver and (surgery OR resection OR hepatectomy) AND (metastatic OR metastases) AND (colon cancer OR rectal cancer OR colorectal cancer OR colon neoplasm OR rectal neoplasm OR colorectal neoplasm) AND (mortality OR mortalities OR death* OR survival).

\section{Discussion of clinical management of patients with colorectal liver metastases}

Patients who present with CLM can generally be divided into three groups: (1) those with resectable disease, (2) those whose metastases may become resectable, and (3) patients who are never going to become resectable. ${ }^{133}$ For the latter group, palliative chemotherapy is the main form of treatment, and these patients have poor long-term outcomes. A clear understanding of chemotherapy use is important when reporting long-term outcomes in patients undergoing hepatectomy, and the benefit of perioperative chemotherapy with surgery for good prognosis of liver disease (solitary, easily resectable metachronous tumors) remains controversial. ${ }^{133}$ The management of patients with CLM should be determined by a multidisciplinary team. ${ }^{128} \mathrm{~A}$ series of studies in liver- limited metastases patients observed a difference in resection by type of multidisciplinary team that managed the patients, with improvement in survival among patients with resection managed with a liver surgeon on the team. ${ }^{128,136-139}$

We were not able to study in detail the effect of chemotherapy on survival. Preoperative chemotherapy has the potential to improve long-term survival after liver surgery for resectable disease. ${ }^{2,27,140-142}$ The use of hepatic arterial floxuridine has been reproduced in only one other study ${ }^{143}$ whereas the use of peri- and postoperative chemotherapy remains controversial. ${ }^{133}$ Adam et al ${ }^{144}$ also reported on the use of "induction" chemotherapy to convert borderline resectable or unresectable liverlimited disease to surgical resectability with curative intent. ${ }^{6}$ Kopetz et al reported that with the approval of new drugs such as oxaliplatin, bevacizumab, and cetuximab in 2004, significant increases in survival overall were observed following use of these drugs. ${ }^{127}$ We identified 21 studies ${ }^{13,14,49,50,52,59,63,67,68,71}$, $73,83,92,100,110,122,123,125,145-147$ that reported survival information for patients treated with induction chemotherapy, primarily treated with a combination of folinic acid, fluorouracil, and oxaplatin or folinic acid, fluorouracil, and irinotecan. When compared to the patients who did not receive preoperative chemotherapy, survival was the same in the chemotherapy-treated groups (median 3.3 years in both groups).
Clinical Epidemiology

\section{Publish your work in this journal}

Clinical Epidemiology is an international, peer-reviewed, open access journal focusing on disease and drug epidemiology, identification of risk factors and screening procedures to develop optimal preventative initiatives and programs. Specific topics include: diagnosis, prognosis, treatment, screening, prevention, risk factor modification, systematic

\section{Dovepress}

reviews, risk \& safety of medical interventions, epidemiology \& biostatical methods, evaluation of guidelines, translational medicine, health policies \& economic evaluations. The manuscript management system is completely online and includes a very quick and fair peer-review system, which is all easy to use. 